\title{
p38 MAPK Signaling in Osteoblast Differentiation
}

\author{
Eddie Rodríguez-Carballo ${ }^{1}$, Beatriz Gámez ${ }^{2}$ and Francesc Ventura ${ }^{2 *}$ \\ ${ }^{1}$ Department of Genetics and Evolution, University of Geneva, Geneva, Switzerland, ${ }^{2}$ Departament de Ciències Fisiològiques \\ II, Universitat de Barcelona and IDIBELL, L'Hospitalet de Llobregat, Barcelona, Spain
}

The skeleton is a highly dynamic tissue whose structure relies on the balance between bone deposition and resorption. This equilibrium, which depends on osteoblast and osteoclast functions, is controlled by multiple factors that can be modulated post-translationally. Some of the modulators are Mitogen-activated kinases (MAPKs), whose role has been studied in vivo and in vitro. p38-MAPK modifies the transactivation ability of some key transcription factors in chondrocytes, osteoblasts and osteoclasts, which affects their differentiation and function. Several commercially available inhibitors have helped to determine p38 action on these processes. Although it is frequently mentioned in the literature, this chemical approach is not always as accurate as it should be. Conditional knockouts are a useful genetic tool that could unravel the role of p38 in

OPEN ACCESS

Edited by:

Ana Cuenda,

National Centre of Biotechnology,

Spain

Reviewed by:

Xose R. Bustelo,

Consejo Superior de Investigaciones

Cientificas, Spain

Francisco Iñesta-Vaquera,

University of Dundee, UK

${ }^{*}$ Correspondence:

Francesc Ventura

fventura@ub.edu

Specialty section:

This article was submitted to

Signaling,

a section of the journa

Frontiers in Cell and Developmental

Biology

Received: 11 March 2016

Accepted: 21 April 2016

Published: 06 May 2016

Citation:

Rodríguez-Carballo E, Gámez B and Ventura F (2016) p38 MAPK Signaling

in Osteoblast Differentiation.

Front. Cell Dev. Biol. 4:40.

doi: 10.3389/fcell.2016.00040 shaping the skeleton. In this review, we will summarize the state of the art on p38 activity during osteoblast differentiation and function, and emphasize the triggers of this MAPK.

Keywords: p38, MAP kinase, bone development, bone homeostasis, osteoblast, cell signaling, cell differentiation

\section{INTRODUCTION}

Two decades ago, the Mitogen-activated kinases (MAPKs) were revealed as key players in skeletal development and bone homeostasis that particularly affect osteoblast commitment and differentiation. Of the three classic MAPKs, scientific evidence predominantly points to $\mathrm{p} 38$ and ERK activities as determining and shaping the skeleton. Remarkably, there are hundreds of reports of in vivo and in vitro studies that analyse the relevant role of p38 and ERK throughout the osteoblastic commitment process, from a mesenchymal progenitor into a fully functional anabolic bone cell. This field of study has been facilitated by the availability of specific inhibitors of MAPK activity. However, these inhibitors may lead to dubious correlations between the specific causal effect of MAPK inhibition and MAPK' role. There are several complete or cell-directed knockouts that provide a broader view of the many effects that MAPKs have on bone differentiation. The purpose of this review is to describe the precise role of p38-MAPK on osteoblast differentiation and the several upstream events that can trigger its activation, in the interests of guiding anabolic therapies for bone-related pathologies.

\section{Bone and Its Constituents}

The skeleton is a very dynamic, calcified organ whose structure is maintained by bone deposition and resorption. During the last decade, new skeletal functions beyond those associated with locomotion and organ protection have been discovered, including fertility, glucose and adipose metabolism, phosphate renal clearance and maintenance of the hematopoietic niche (Karsenty and Ferron, 2012). Structurally, bone tissue is composed of different cells and an extracellular matrix (ECM). This matrix has two components: one organic and another inorganic. The latter 
is mainly formed by hydroxyapatite, which represents $99 \%$ of the body's calcium and $80 \%$ of the body's phosphate. The organic component is composed of collagen fibers, glycosaminoglycans, proteoglycans and glycoproteins. Collagen $\mathrm{I}$ is the most common protein in bone, accompanied by proteins such as bone sialoprotein (IBSP) and osteonectin (SPARC). Moreover, certain cytokines, such as TGF- $\beta$ (transforming growth factor- $\beta$ ) and BMP (bone morphogenetic protein), remain bound to ECM fibers and can be freed during resorption processes (Dallas et al., 2002; Gregory et al., 2005).

Bone formation can be explained from two perspectives: embryological origin, and ossification. Embryologically, facial skeletal structures are derived from the ectoderm, while the axial and appendicular skeletons emerge from the paraxial mesoderm and the lateral mesoderm plate, respectively (Berendsen and Olsen, 2015). Ossification can be defined as endochondral or intramembranous. The latter mechanism occurs directly from mesenchymal condensation, in which mesenchymal stem cells (MSCs) differentiate into osteoblasts (Percival and Richtsmeier, 2013). Endochondral ossification is a very well-characterized process that takes place in long bones. A cartilage cast is invaded by mesenchymal progenitors, which leads to the appearance of a chondrocyte-enriched growth plate that allows longitudinal bone growth, and an osteoblast-driven ossification center in each epiphysis. Concurrently, cells in the periphery of the cartilage cast will differentiate into osteoblasts, which create the bone cortical structures (Long and Ornitz, 2013).

Once formed, several cells from different origins end up composing the skeleton. The osteoblast is considered the most anabolic bone cell, due to its ability to secrete and calcify the extracellular matrix. Osteoblasts are cuboidal cells that lie on the surface of bone matrix (Long, 2012). They are derived from MSCs that can also differentiate into adipocytes, myoblasts, chondrocytes and fibroblasts (Augello and De Bari, 2010). Differentiation into osteoblasts is a complex process, in which serial commitment landmarks are achieved sequentially (Figure 1). It is accepted that during the first steps of commitment, these progenitors can still express stem markers and chondrocyte markers (e.g., SOX9). Pre-osteoblasts have already lost signature genes of the chondrogenic profile, and they start to express certain specific markers associated with the osteoblast linage, although they cannot produce extracellular matrix yet. These osteoblast-specific genes include transcription factors such as RUNX2, DLX5 and SP7 (Osterix). Soon after, other markers that are related to matrix formation start to be expressed: osteocalcin (Bglap2), fibromodulin (Fmod), and bone sialoprotein (Ibsp), among others (Franceschi et al., 2007; Long, 2012).

Once osteoblasts have reached the bone formation phase, four outcomes may occur: (1) they get trapped in bone matrix as osteocytes; (2) they become bone-lining cells; (3) they enter apoptosis; and (4) they can trans-differentiate into cells that depose chondroid tissue (Franz-Odendaal et al., 2006; Rochefort et al., 2010). Typically, osteocytes are closed in lacunae inside calcified bone. In the beginning of this embedding process, young osteocytes still look like secretory cells and express osteoblast markers. Some of these will be lost during terminal differentiation, while mature osteocytic markers appear (Rochefort et al., 2010). Osteocytes tend to express higher levels of FGF23 (fibroblast growth factor 23), NPY (neuropeptide-Y), RLN (reelin), SOST (sclerostin), DMP1 (dentin matrix acidic phosphoprotein 1), PHEX (phosphateregulating neutral endopeptidase, X-linked), PDPN (gp38/E11), while matrix metalloproteinases and collagen proteins are more closely related to the osteoblast state (Paic et al., 2009). Recently, relevant functions have been attributed to osteocytes, including bone remodeling and regulation of the hematopoietic stem cell niche (Asada et al., 2013). Remarkably, osteocytes show dendritic-like cytoplasmic prolongations (5060 per cell) that form a canalicular system inside bone (Rochefort et al., 2010; Klein-Nulend et al., 2013). These structures serve for sensing and interpreting mechanical inputs like bone loading (Rochefort et al., 2010; Xu et al., 2012).

Bone resorption is the process by which the mineral extracellular matrix is degraded. This process is primarily carried out by osteoclasts, which are derived from monocytes and macrophages (Ikeda and Takeshita, 2016). They proliferate in the bone marrow, and fuse to give rise to multinuclear reabsorbing cells close to the resorption region. Osteoclast progenitors express RANK (receptor activator of nuclear factor$\kappa \mathrm{B}$ ), which interacts with RANKL (receptor activator of nuclear factor- $\kappa B$ ligand). Several cells produce RANKL, including osteoblasts, osteocytes, stromal cells and lymphocytes (O'Brien et al., 2013; Ikeda and Takeshita, 2016). The RANK activation process can be antagonized by osteoprotegerin (OPG), a RANKL competitor that is mainly expressed by osteoblasts (Simonet et al., 1997). Other factors contribute to the activation and function of osteoclasts, such as vitamin D and SOST, which is also mainly produced by osteocytes (van Bezooijen et al., 2005).

\section{THE MAPK SIGNALING PATHWAYS}

\section{Introduction to the MAPKs}

MAPKs are a family of enzymes that are implicated in a series of processes in which extracellular stimuli (e.g., environmental stress, growth factors and cytokines) are transduced into different cellular actions. In some cases, they act as a signaling hub in which different signaling pathways converge to activate a MAPK in a given time frame or tissue. Conventional MAPK members are the extracellular signal-regulated kinases $1 / 2$ (ERK1/2) and ERK5, c-Jun amino (N)-terminal kinases 1/2/3 (JNK1/2/3), and the p38 isoforms (p38 $\alpha$, p38 $\beta$, p38 $\gamma$, and p38 ) (reviewed in Cargnello and Roux, 2011). All of them contain a Ser/Thr kinase domain, activated by phosphorylation by other Ser/Thr kinases. Thus, MAPK signaling constitutes a series of phosphorylations, in which several elements are at play until the final substrate is targeted. Therefore, once stimuli have reached the cell, MAPKK kinases (MAP3K) are activated and phosphorylate MAPK kinases (MAP2K), which in turn phosphorylate and activate the aforementioned MAPKs. Each 


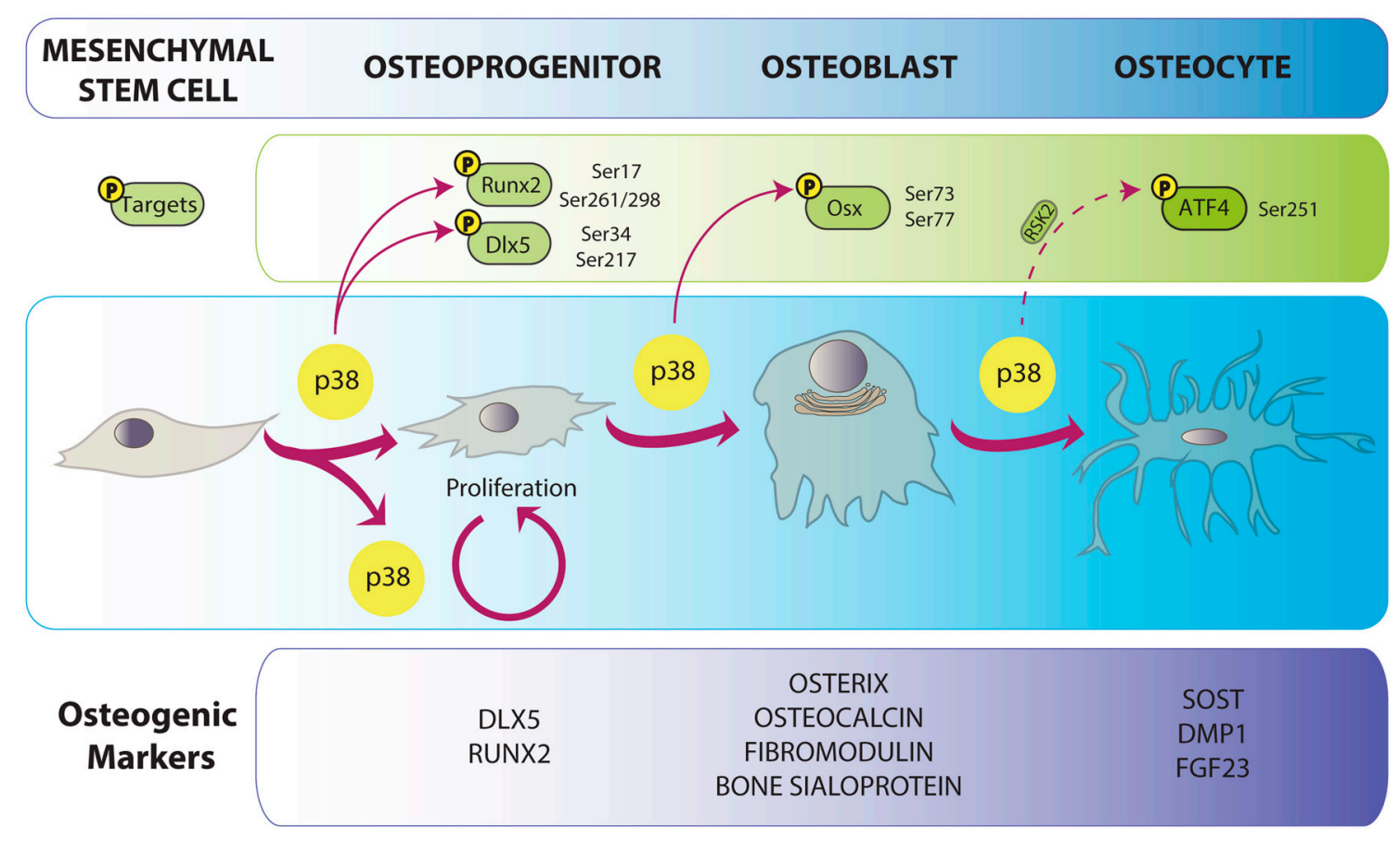

FIGURE 1 | p38 implication in osteoblast differentiation. Osteoblast differentiation is characterized by the expression of a specific cohort of proteins depicted in the lower panel. p38 is related both to differentiation and proliferation of bone progenitors. p38-mediated phosphorylation promotes progression in osteogenesis by the enhancement of the activity or expression of osteoblast-specific transcription factors genes. Direct arrows indicate direct phosphorylation while dashed arrow indicates indirect action of p38. Phosphorylated residues are specified for every target.

MAPK group has its own series of upstream activators, thus each represents a specific signaling cascade (Cuadrado and Nebreda, 2010).

\section{JNK Signaling in Osteoblastic Differentiation}

The role of JNK in osteoblastogenesis seems to be somewhat contradictory, with different functional outputs depending on the study. For instance, interleukin-1 $\beta$ (IL1 $\beta$ ) and tumor necrosis factor- $\alpha(\mathrm{TNF} \alpha)$ favor JNK activation and this effect is determinant for osteoblast differentiation of human periosteal cells (Hah et al., 2013). Moreover, Liu et al. found that inhibition of the JNK route by chemical inhibitors or siRNAs led to decreased mineralization and downregulation of several osteogenic markers, while its activation by a constitutive active form favored osteogenesis. These effects were, at least in part, due to reduced SMAD6 binding to BMPRI (BMP receptor I), which allows SMAD1 to access the receptor (Liu et al., 2011). However, another effect of JNK activation might be to negatively regulate osteogenesis. JNK1 reduces RUNX2 transcriptional activity by phosphorylation at Ser104 (Huang et al., 2012). In addition, the inhibition of JNK with SP600125 in human MSC increases ALP activity induced by BMP-2 (Biver et al., 2014). This inhibitory action may also integrate SMAD1 signaling, as MAPK phosphorylation is necessary for GSK3 $\beta$ (Glycogen synthase kinase $3 \beta$ )-induced SMAD1 degradation (Fuentealba et al., 2007; Biver et al., 2014).

\section{ERK Signaling in Osteoblastic Differentiation}

Both ERK1 and ERK2 are expressed in osteoblasts and have relevant functions in bone metabolism. There is genetic evidence of the implication of the ERK pathway in osteogenesis. First, the expression of a dominant negative form of MEK1 under the regulation of the osteocalcin promoter (mOG2:Mek1DN) exhibits calvarial and clavicular defects, which phenocopy the Runx2 deficiency. The phenotype of Runx $2^{+/-}$is recovered by crossing these mutant mice with a constitutive active form of MEK1 (mOG2:tgMek1SP) (Ge et al., 2007). Matsushita and collaborators generated the double mutant $\mathrm{Erk1}^{-/-} ; E r k 2^{\text {Prx1:Cre }}$. They showed the positive effect of ERK1 and ERK2 on osteoblast differentiation, and the inhibitory effect of these MAPKs on chondrocyte differentiation at the perichondrium. In addition, ERK has certain effects on RANKL in these cells, which has an impact on osteoclast activation (Matsushita et al., 2009).

RUNX2 phosphorylation is the action of ERK signaling on osteoblast specification that has been most widely studied. First, use of the MEK1 inhibitor PD98059 blocks osteocalcin induction by RUNX2 (Xiao et al., 2000). U0126, another MEK1/2 inhibitor, halts the expression of osteocalcin and Ibsp mediated by BMP7 and ascorbic acid (Xiao et al., 2002a). In addition, FGFs activates pERK, and subsequently a phosphorylated form of RUNX2 is detected. Again, these effects can be blocked by U0126 (Xiao et al., 2002b). Finally, the same group proved the existence of four serine residues (Ser43, Ser301, Ser319, and 
Ser510) targeted by ERK1/2. Ser301 and Ser319 were found to be responsible for RUNX2 activating abilities (Ge et al., 2009). The increase in pRUNX2 transcriptional activity induced by ERK could be attributed to the binding of cofactors such as CREB, $\mathrm{CBP} / \mathrm{p} 300$ or vitamin D receptor (Sierra et al., 2003), as seen in p38 phosphorylation (Greenblatt et al., 2010). Related to this, an increase in cytoplasmatic pERK has been associated with an increment in nuclear RUNX2 upon overexpression of the transmembrane glycoprotein CD99, which implies that RUNX2 phosphorylation takes place in the cytoplasm (Sciandra et al., 2014).

NF1 (neurofibromatosis type I) is a GTPase-Activating Protein that turns off Ras action on ERK signaling. The inactivating mutation of NF1 seems to have different results depending on the developmental status at which deletion takes place (Greenblatt et al., 2013). In fact, analysis of the osteoblastspecific mutant of $N f 1$ shows a blunted response to BMP-2 that is overcome when ERK was inhibited by U0126 (de la Croix Ndong et al., 2015). Besides differentiation, ERK is related to the activity of cyclinD1, enhanced by PTH and PTHrP, and favoring osteoblast proliferation (Datta et al., 2007). Recently, it has been shown that ERK regulates the antiapoptotic and proliferative effects of EGF on osteoprogenitors (Chandra et al., 2013).

\section{p38 MAPK Cascade}

The p38 MAPK family is composed of four proteins: p38 $\alpha$

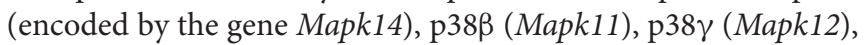
and $\mathrm{p} 38 \delta$ (Mapk13). Their coding genes have a distinct tissue distribution and they appear differentially expressed, being Mapk14 the most highly expressed (Cuadrado and Nebreda, 2010). p38 MAPKs are substrates for three MAP2K (MKK6, MKK3, and MKK4). The contribution of each of these MAP2K to p38 MAPKs activation depends on the stimulus and the cell type (Alonso et al., 2000; Brancho et al., 2003; Remy et al., 2010; Figure 2). The MAP3Ks that lead to p38 MAPKs activation are ASK1, DLK1, TAK1, TAO1, TAO2, TPL2, MLK3, MEKK3, MEKK4, and ZAK1 (Cuadrado and Nebreda, 2010). p38 $\alpha$ can also be autophosphorylated, due to activation through ZAP70, p56 $6^{\text {lck }}$, and TAB1, and downregulation of Cdc47 (Cuadrado and Nebreda, 2010).

It is known that there are several scaffold complexes along this route that facilitate MAPK-MAP2K interaction or locally increase the concentration of effectors of the MAPK cascade, driving fine spatio-temporal regulation. The most commonly reported molecules related to this function belong to the protein family named JIP (from c-Jun NH2-terminal kinase-interacting protein) that can tether p38 and JNK to their upstream MAP2K. JLP, which have the isoforms JIP4 and SPAG9 (Kelkar et al., 2005; Dhanasekaran et al., 2007) and JIP2, have been implicated in regulating p38 by tethering to MKK3, MEKK3, and MKK4 (Dhanasekaran et al., 2007). The role of these scaffold proteins in regulating MAP2K action could be of special interest, as it has been shown that constitutive activation of MKK3 or MEK1 has deleterious effects on BMP-induced osteoblastogenesis (Huang et al., 2014). Apart from JIP proteins, there are other potential MAPK scaffolds: RACK1 (Arimoto et al., 2008), KSR-2 (Liu et al., 2009), Sec8 (Tanaka et al., 2014) and the osmosensing scaffold for Rac-MEKK3-MKK3 (OSM) (Dhanasekaran et al., 2007). Out of these, Mapk8ip2 (JIP2) is detected in the developing skeleton, and Exoc4 (Sec8 protein), which interacts with JIP4, is expressed in bone cells (www.genecards.org and www.eurexpress.org). Besides the aforementioned proteins, TAK1 and TAB1 could also be considered a sort of scaffold proteins, as they facilitate the recruitment and activation of upstream effectors of the p38 pathway. However, no MAPK scaffold proteins have been investigated in osteoblast development in vivo to date.

p38 MAPKs are inactivated mainly by dephosphorylation by certain phosphatases belonging to the DUSP family (Bermudez et al., 2010). Moreover, the catalytic activity of p38 $\alpha$ is modulated according to how many and which threonine or tyrosine residues are phosphorylated in the activation loop (Zhang et al., 2008). Like any other relevant molecule, p38 is also regulated by mechanisms such as acetylation, protein degradation and stabilizing cofactors and, obviously, changes in the expression of their coding genes (reviewed in Cuadrado and Nebreda, 2010). p38 $\alpha$ is localized in the nucleus and the cytoplasm (Raingeaud et al., 1995). Its localization depends on activation and on active transport, as p38 does not have a nuclear localization signal. It is known that DNA damage favors phosphorylation and nuclear accumulation of $\mathrm{p} 38 \alpha$, probably by releasing $\mathrm{p} 38 \alpha$ from TAB 1 or MK2, as they act as cytoplasmatic anchors (Wood et al., 2009).

\section{p38 AND MESENCHYMAL DIFFERENTIATION}

The p38 pathway has been implicated in the differentiation of several mesenchymal cells. Most reports on this topic have been cell-based studies in which activation or inhibition of the pathway was achieved mainly pharmacologically.

\section{Adipocyte Differentiation}

There is some controversy about the role of p38 in adipogenesis. Some authors claim that it depends on the species or on the specific cell type used in vitro, where different factors could be at play. The generation of a tissue-specific knockout would shed light on this theme. p38 was linked to the phosphorylation of $\mathrm{C} / \mathrm{EBP} \beta$ and the expression of PPAR $\gamma$ (peroxisome proliferator-activated receptor- $\gamma$ ) in 3T3-L1 cells (Engelman et al., 1998). In fact, the overexpression of an active form of MKK6 favors adipocyte differentiation (Engelman et al., 1999). (2S)-7,4'-dihydroxy-8-prenylflavan also stimulates the adipogenic program and glucose uptake via p38 (Ji et al., 2015). Contrary to the main current of knowledge regarding BMPdirected osteogenesis, this cytokine also stimulates adipogenesis of mesenchymal precursors via p38, probably involving SMAD proteins as well (Hata et al., 2003; Huang et al., 2009). Regarding adipocyte physiology, one of the few experiments performed on living animals was the administration of the p38 inhibitor FR167653. This treatment significantly reduced weight gain, fat depots and adipocyte size (Maekawa et al., 2010). p38 also seems relevant for brown adipocyte commitment, as seen with DUSP10 induction (Choi et al., 2013) or the inhibitory effects of silica nanoparticles (Son et al., 2015). Indeed, NPY seems to 

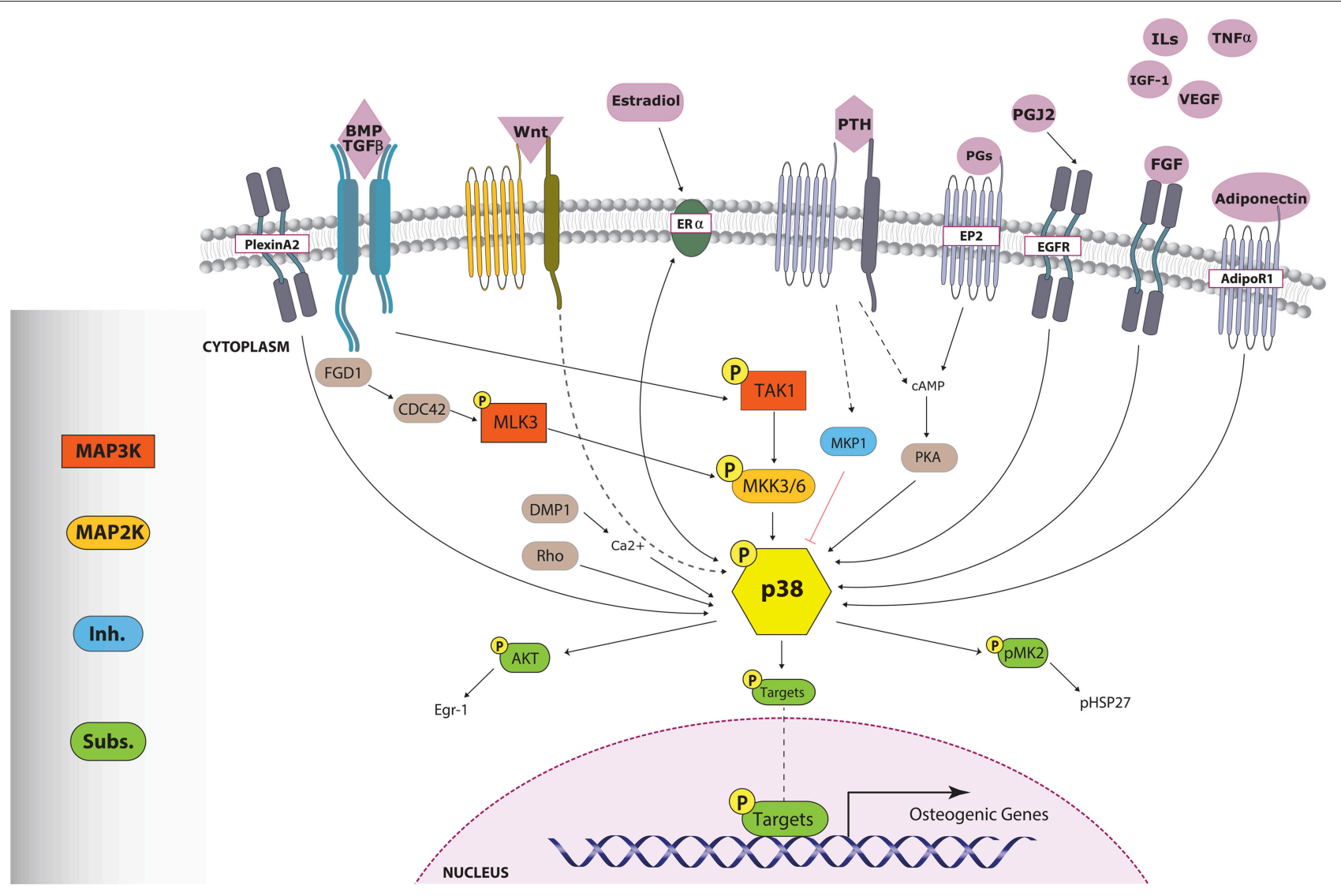

FIGURE 2 | p38 triggers involved in osteogenesis. Numerous stimuli, through distinct mechanisms, lead to p38 MAPK phosphorylation. Activated p38 phosphorylates important osteoblast-related transcription factors, which will enhance osteogenic gene expression. pp38 can also trigger other pathways through the activation of cytoplasmic-acting substrates such as AKT and pMK2. Sharp arrows indicate direct activation. Dashed arrows indicate an unknown or indirect mechanism of action while the red flat-tipped arrow denotes inhibition.

affect the brown fat gene program and reduce p38 and CREB phosphorylation (Wan et al., 2015).

Other studies describe contrary effects. For example, p38 activates CHOP, a negative regulator of C/EBP $\beta$ (Wang and Ron, 1996), and also blocks NFATc4, which is a transcription factor for Pparg (Yang et al., 2002). In chicken adipocytes, adiponectin prompts a cascade through p38/ATF2 that inhibited CEBP $\alpha$, and affects preadipocyte differentiation (Yan et al., 2013). Adipogenesis conducted by microtubule affinity-regulating kinase 4 (Marc4) depends on JNK activation and p38 downregulation in 3T3-L1 (Feng et al., 2014). p38 activity seems to decrease during adipocyte differentiation, and inhibition of p38 augments PPAR $\gamma$ transactivation and other adipocyte markers. Furthermore, p38-deficient MEFs have increased expression of adipogenic markers such as adiponectin or leptin (Aouadi et al., 2006). Strikingly, the same group proposed a positive role for $\mathrm{p} 38$ during human adipocyte differentiation, mainly based on C/EBP $\beta$ phosphorylation (Aouadi et al., 2007). Ferguson et al. linked the role of DUSP1 phosphatase to the deactivation of p 38 and ERK during the first steps of preadipocyte commitment, which establishes a framework for self-regulatory feedback (Ferguson et al., 2016).

\section{Myoblast Differentiation}

p38 MAPK isoforms have multiple roles in muscle development and homeostasis in the adult. They control self-renewal, proliferation, asymmetric division and differentiation of satellite cells (Brien et al., 2013; Bernet et al., 2014). Early studies show higher $\mathrm{p} 38 \alpha, \beta$, and $\gamma$ levels during myoblast maturation, and that p38 inhibition blocks muscle-specific gene transcription (Cuenda and Cohen, 1999; Zetser et al., 1999). p38 activity is absolutely required for the transition from proliferating satellite cells into terminally differentiated myoblasts (Puri et al., 2000). This control of the muscle-specific gene program is performed through multiple steps that finally lead to activation of key myogenic transcription factors. For instance, p38 induces the transcriptional activity of MEF2 family members through direct phosphorylation at Thr293 (Wu et al., 2000; Lluis et al., 2006). In addition, p38 also phosphorylates and activates the obligate MyoD partner E47 (Lluis et al., 2005). Several reports indicate that p38 activity is required for chromatin remodeling, to allow access and stabilization of the binding of myogenic transcription factors to myogenic loci (Lluis et al., 2006). These mechanisms involve histone acetylation by PCAF and p300, and recruitment of the SWI/SNF complex (Simone et al., 2004; de la Serna et al., 
2005). Subsequently, p38 activity is important for myocyte fusion and myofibrillogenesis (Gardner et al., 2015).

More recently, the role of p38 in muscle development has been extended to the activation of satellite cells during muscle regeneration. Muscle regeneration takes place in a highly inflammatory environment, and inflammatory cytokines such as IL6 or TNF $\alpha$ activate p38 (Li et al., 2014c). Signaling from $\mathrm{p} 38 \alpha / \beta$ is involved in the exit of satellite cells from quiescence (Jones et al., 2005; Brien et al., 2013), and arranges asymmetric division and self-renewal (Troy et al., 2012; Bernet et al., 2014). Importantly, skeletal muscle aging results in a loss of muscle mass and regenerative capacity. These defects arise because satellite cells from aged mice fail to self-renew and increase p38 activity. Since pharmacological manipulation of $\mathrm{p} 38 \alpha / \beta$ activity ameliorates these age-associated defects, this could be a potential therapeutic opportunity to treat muscle wasting (Bernet et al., 2014).

\section{Osteoblast Differentiation}

One of the first studies to indicate that p38, ERK, and JNK were activated during osteoblast differentiation of human MSC was Jaiswal et al. (2000). Gallea and collaborators showed that ERK and p38 activation in $\mathrm{C} 2 \mathrm{C} 12$ favored osteoblast determination (Gallea et al., 2001). Soon after, it was shown that the inhibitor SB203580 impairs MC3T3 pre-osteoblast differentiation and the expression of osteoblast markers such as ALP, OC, and collagen (Suzuki et al., 1999, 2002). As will be seen later, many stimuli have been assayed as triggers of p38 activation in osteoblasts, to explore their osteogenic activities.

\section{THE STUDY OF p38 IN BONE: DIFFERENT STRATEGIES, THE SAME GOAL}

\section{Knockouts of p38}

Different groups have generated germline knockout mice in which the p38 pathway is mutated. It should be stated that p38 $\alpha$ is the most highly expressed isoform of p38-MAPK in osteoblasts (Greenblatt et al., 2010; Rodriguez-Carballo et al., 2014). Embryos with a homozygous deletion of $p 38 a$, as well as embryos with a double knockout of $M k k 3 / M k k 6$, die during embryogenesis, while mutations of Map2k3 (MKK3), Map2k6 (MKK6), Mapk11, Mapk12, and Mapk13 are viable (Cuadrado

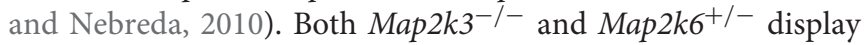
severe skeletal defects in long bones, while only Map $2 k 3^{-/-}$show abnormalities in craniofacial bone structures (Greenblatt et al., 2010). The embryonic lethality of Mapk14 loss is associated with neural and cardiac defects (del Barco Barrantes et al., 2011). Initially, a lack of Mapk11 was not implicated in severe defects (Beardmore et al., 2005), although later it has been associated with some mild bone defects (Greenblatt et al., 2010). The Mapk13 $13^{-1}$ mice has reduced sensitivity to skin carcinogenesis (Schindler et al., 2009), as well as higher insulin secretion and tolerance to glucose (Sumara et al., 2009). No bone phenotype was described in the original article in which Mapk12-/- and Mapk13-/- were generated (Sabio et al., 2005), or in successive studies.
In the last 5 years, three studies reported the use of bone conditional knockouts affecting the p38 pathway in osteoblasts (reviewed in Thouverey and Caverzasio, 2015a). Greenblatt and collaborators' integral approach involved analysing the deletions of different effectors of the pathway. The conditional deletion of MAP3K TAK1 in pre-osteoblasts leads to defects in osteoblast differentiation and bone formation that affects the entire skeleton. In fact, the phenotype resembles human cleidocranial dysplasia, which is related to RUNX2 mutations. Indeed, one of the conclusions of the study is that RUNX2 is a target of p38 kinase activity, which is essential to the transactivation function of RUNX2 (Greenblatt et al., 2010). Craniofacial defects are mainly associated with the function of TAK1, MKK3, and p38 $\alpha$, particularly when it affects preosteoblasts, as with the use of an Osterix-driven recombinase (Greenblatt et al., 2010; Rodriguez-Carballo et al., 2014). No cranial phenotype was described when an osteocalcin-Cre animal model was used (Thouverey and Caverzasio, 2012). Additionally, with the latter approach, a post-natal bone acquisition defect starts only after 5 weeks of age and disturbs trabecular and cortical bone volumes of mice (Thouverey and Caverzasio, 2012). A doxycycline-induced recombinase can be used to monitor the impact of $\mathrm{p} 38 \alpha$ deletion in osteochondroprogenitors at different time points. When the deletion starts at 3 weeks of age, the anabolic defects are mainly trabecular at 30 weeks of age, and cortical at 60 weeks. When the deletion starts in young adults (circa 8 weeks of age), only cortical defects are encountered. This means that $\mathrm{p} 38 \alpha$ function is particularly important at different stages of osteoblast commitment throughout life (RodriguezCarballo et al., 2014). Interestingly, this low bone mass model was also used to hypothesize about the crosstalk between the skeleton and the adipose tissue (Rodriguez-Carballo et al., 2015).

\section{Pharmacological Inhibitors of p38}

The use of knockout models represents the most faithful, general analysis of MAPK activity on tissues. Primary osteoblast cultures from these knockout animals, or the manipulation of pathway effectors (via constitutive activation or dominant negative forms), allows molecular analysis in specific models. However, the most frequent approach is the use of selective inhibitors of the different MAPKs. The most common p38 inhibitor is the pyridinyl imidazole molecule SB203580 (Lee et al., 1994; Cuenda et al., 1995). This is considered a highly selective $\mathrm{p} 38 \alpha / \beta$ inhibitor and has been widely used for more than 20 years (it had over 6000 PubMed entries up to 2015). Nevertheless, it has been shown that it can inhibit other kinases, such as GAK, CK1, RIP2, RAF, and GSK3, and the formation of ZMP from AICAR (Bain et al., 2007). The SB203580 inhibitor has been assayed in some inflammatory skeletal conditions, such as arthritis (Badger et al., 1996). BIRB0796 is even more powerful at blocking $\mathrm{p} 38 \alpha / \beta$, but at moderate doses it can also halt the activity of $\mathrm{p} 38 \gamma$, p38 $\delta$, and JNK2 22 (Bain et al., 2007). SD-822 is considered a more selective p38 $\alpha$ inhibitor (Koppelman et al., 2008) and has been used in studies of osteoarthritis to reduce the outcome of the disease (Medicherla et al., 2006). Caverzasio and colleagues showed the potential benefits of this inhibitor for the treatment 
of osteoporosis, as it reduces osteoclast activity (Caverzasio et al., 2008).

\section{p38 Osteogenic Targets}

The osteogenic potential of p38 kinase is related to its capacity to phosphorylate and increase the activity of some key osteogenic transcription factors. As explained above, both ERK and p38 can phosphorylate RUNX2, boosting its transcriptional potential (Ge et al., 2009, 2012; Greenblatt et al., 2010; Artigas et al., 2014). In addition, our group has described new p38 phosphorylation targets in recent years. For instance, BMP2 stimulus increases DLX5 transactivation of the $S p 7$ (Osx) promoter through a feed-forward mechanism. First, Dlx 5 mRNA levels are elevated by BMP treatment (Miyama et al., 1999; Luo et al., 2001; Holleville et al., 2003; Ulsamer et al., 2008; Rodriguez-Carballo et al., 2011). Then, post-translationally, DLX5 is phosphorylated by p38 MAPK at serines Ser34 and Ser217, which facilitates the recruitment of p300 (Ulsamer et al., 2008; Figure 1). Another DLX member, Dlx3, is also induced by BMP-2. In this case, it occurs through cooperation between SMAD5 and pp38 as they translocate to the nucleus and exert their function on the Dlx3 promoter (Yang et al., 2014). These p38-activated osteogenic events continue with the phosphorylation of Osterix at serines Ser77 and Ser33. As for DLX5, these modifications represent an increase in the transcriptional ability of OSX by helping to recruit p300 and BRG-1 (Ortuno et al., 2010, 2013). It was also shown that OSX can cooperate with RUNX2 to induce Colla1 (Ortuno et al., 2013). In fact, soon after, it was proven that indeed OSX and RUNX2 bind each other and cooperate to increase their transcriptional power. This interaction requires the action of p38 and ERK MAPKs, as mutation of the phosphorylation sites of RUNX2 and OSX prevented their interaction (Artigas et al., 2014).

In addition to these classic osteogenic targets, p38 can phosphorylate ATF members at threonines Thr69 and Thr71, as well as CREB at the serine Ser133. Both ATF and CREB are transcriptional co-factors and, again, these phosphorylations increase their transactivation capacity, including the recruitment of histone acetyltransferase p300 (Livingstone et al., 1995; Waas et al., 2001). More importantly, ATF4 phosphorylation by RSK2 has been shown to be absolutely required for bone development (Yang et al., 2004). Both ERK and p38 turn on RSK2 in different cell types (Siebel et al., 2013; Czaplinska et al., 2014), which then can lead to activation of ATF4 by its phosphorylation at Ser251 (Yang et al., 2004).

\section{Signaling Interaction between MAPKs in Osteoblasts}

Very few studies have focused on the degree of interaction between different MAPK pathways. The crosstalk between pathways can be both opposed and cooperative. As a rule of thumb, inhibition of one MAPK pathway activates the other. The dominant negative form of $\mathrm{Mek}(\mathrm{MekDN})$ favors the activation of p38, while the constitutively active form has the opposite effects. The same goes for ERK when Mkk6dn and Mkk6sp are used (Ge et al., 2012). Nevertheless, blocking of both pathways by SB203580 and U0126 has deleterious consequences on calvaria mineralization in organotypic cultures (Ge et al., 2012). Similarly, some reports showed that osteogenic effects require cooperation between JNK and p38 signaling (Guicheux et al., 2003).

\section{p38 and Cell Migration}

Other actions besides participation in cell proliferation and differentiation are attributed to $\mathrm{p} 38 \mathrm{MAPK}$, including control of cell migration. This function is vital to understand p38 MAPK's role in physiological processes, such as chemotaxis, fracture healing and wound closure, as well as the consideration of p38 as a target to diminish the invasiveness of cancer cells. The first model in which p38 was associated with cell motility was endothelial cells. SB203580 inhibited VEGF-induced cell migration (Rousseau et al., 1997). Subsequently, p38 was shown to be essential to cell migration in a plethora of different cell types. In other studies, p38 is negatively linked to cell motility. The loss of $\mathrm{p} 388$ has been associated with an increase in cell motility and proliferation of squamous cancer cells (O'Callaghan et al., 2013). In C2C12, interleukin-17 inhibits cell migration by downregulating urokinase through p $38 \alpha$ activation (Kocic et al., 2013).

As said, the positive link between p38 and cell movement appears evident. In skeletal cells, p38 activation is positively related to cytoskeletal reorganization and stimulation of cell motility. In 2004, it was reported that PDGF stimulated the proliferation and migration of MC3T3 through different MAPKs. This migration halted when p38 was inhibited, but not when JNK or ERK were blocked (Mehrotra et al., 2004). The flavonoid quercetin impairs cell migration in osteoblastic cells, but the inhibition of ERK and p38 stops this effect (Nam et al., 2008). Our group studied the function of BMPs as chemotactic agents and as inductors of actin cytoskeletal reorganization in mesenchymal cells. These events require the activation of two pathways: PI3K/CDC42/LIMK1 and p38/MAPKAP2/HSP25. Moreover, in fibroblasts depleted for Mapk14 or Mapkapk2, BMP-2 signaling could not favor actin cytoskeletal reorganization and induction of movement (Gamell et al., 2008, 2011). Another interesting aspect of p38 in osteoblastic matrix remodeling is attributed to its role in a model of collagen contraction (Parreno and Hart, 2009).

Fracture assays can be performed in vivo and in vitro. In a model of fracture healing in rat, TNF $\alpha$ stimulates the proliferation and migration of bone marrow MSCs to the fracture site. This effect was explained by the activation of p38 and inhibition of differentiation in this area, as shown in vitro (Zhou et al., 2006). These migratory effects of TNF $\alpha$ were corroborated in vitro with MSCs (Fu et al., 2009).

PTH treatment stimulates amphiregulin in osteoblasts. This osteoblast expression enhances the migration and recruitment of close-by mesenchymal progenitors, due to signaling on EGFR through PI3K and p38 (Zhu et al., 2012). SDF-1 (stromal cellderived factor-1) is described as an inductor of migration of umbilical cord MSCs through activation of AKT, ERK and p38 (Ryu et al., 2010). In fact, shear stress stimulation of JNK and p38 signaling can also provoke SDF-1 secretion in human mesenchymal cells, which activates the CXCR4 receptor and favors migration (Yuan et al., 2012). 


\section{SIGNALING TRIGGERS p38 IN OSTEOBLAST FUNCTION}

The great variety of stimuli that can activate MAPK and the extended use of specific inhibitors have facilitated the evaluation of the MAPK role in osteogenesis (Figure 2). These factors make it easier to design experimental studies to validate different osteogenic treatments. However, conclusions about the specific action of a given treatment that is supposed to affect MAPK signaling should be treated with caution. First, inhibition of a MAPK could favor the activation of another MAPK. Secondly, different inhibitors have associated effects that have not been characterized fully. Third, MAPK pathways are stress-activated cascades, and if there are no proper controls, osmotic stress could account for part of the related effects. And fourth, too often researchers do not ascertain which mechanism activates $\mathrm{p} 38$.

\section{Osteogenic Hormones and Growth Factors p38 Is a Non-Canonical TGF $\beta / B M P$ Signaling Pathway}

The stimulation of $\mathrm{p} 38$ by BMP through TAK1 was first observed in the PC12 cell line (Iwasaki et al., 1999). Then, it was shown how BMP and TGF $\beta$ activate p38, ERK and JNK in different mesenchymal cells, including osteoblasts. The involvement of these MAPKs has been observed in different osteogenic in vitro models (Gallea et al., 2001; Viñals et al., 2002; Guicheux et al., 2003). A recent report showed that $\mathrm{p} 38$ was predicted to account for $20 \%$ of the phospho-residues identified after treatment of MSCs with BMP (Halcsik et al., 2013). TGF- $\beta$ provokes the phosphorylation of $\mathrm{p} 38$, ERK and JNK in a very rapid manner in MC3T3 and primary osteoblasts (Arnott et al., 2008). p38 and ERK are needed for Col3a1 expression in UMR cells under BMP or TGF- $\beta$ treatment (Selvamurugan et al., 2004). In addition, p38 is necessary for TGF- $\beta$-induced synthesis of VEGF in MC3T3 (Tokuda et al., 2003). Although essentially independent, there is a certain level of cross-regulation between SMADs and p38. For example, in human osteoblast cells, inhibition of p38 by SB203580 seems to make SMAD1 phosphorylation and its nuclear accumulation difficult (Noth et al., 2003). In addition, both signaling pathways are needed for BMP5 induction of limb development (Zuzarte-Luís et al., 2004). Nevertheless, p38 and ERK should be inhibited by BMP4 to guarantee self-renewal and stemness (Qi et al., 2004).

BMP signal transduction through p38 has been studied in several cell models. As mentioned previously, the onset of the cascade begins, as for SMADs, at BMP receptor (BMPR) level. Both SMADs and p38 need the kinase activities of BMP receptor complexes. After receptor triggering, MAP3K TAK1 is activated. Mechanistically, it is well-established that TGF-b regulates the TAK1/p38 pathway through recruitment and ubiquitylation of TRAF6 by activated receptor complexes (Sorrentino et al., 2008; Yamashita et al., 2008; Figure 3). BMPRs form a complex with NRAGE, TAK1, XIAP, and TAB1, which favor p38 activation (Yamaguchi et al., 1999; Kendall et al., 2005). Interestingly, a member of the insulin/Rln family, named Relaxin, can phosphorylate TAK-1 and cooperate with BMP-2 in promoting osteogenesis by enhancing the BMP activation of the p38 signaling pathway (Moon et al., 2014).

\section{Wnt Signaling}

The Wnt pathway interacts with p38 at different levels. Wnt can activate p38 through Disheveled proteins, as the silencing of $D v l-3$ avoids Wnt3a-induced ATF2 phosphorylation (Bikkavilli et al., 2008). At the same time, p38 can reinforce the $\mathrm{Wnt} / \beta$ catenin pathway. In COS-7 and endodermic F9 cells, p38 $\alpha$ inactivates GSK $3 \beta$ by phosphorylating its Ser9, allowing $\beta$ catenin to accumulate. Indeed, blocking the p38 pathway affects the triggering of Wnt3a downstream events (Bikkavilli et al., 2008). The activation of both p38 and ERK by Wnt3a, and its effects on pre-osteoblasts' commitment without disturbing proliferation, have also been reported (Caverzasio and Manen, 2007). In dental pulp cells, BMP-2 facilitates Lef1 expression and $\beta$-catenin nuclear accumulation. The authors claimed that this was due in part to $\mathrm{p} 38$, as the inhibitor SB20350 prevented these effects (Yang et al., 2015b). Very recently, Ehyai reported that p38-mediated phosphorylation on MEF 2 enhances $\beta$-catenin nuclear accumulation (Ehyai et al., 2015). The convergence of both pathways has also been demonstrated at the level of the WNT receptor LRP6. In HEK 293, LRP6 phosphorylation by the MAPKs p38, ERK1/2, and JNK is key for the recruitment of the multiprotein degradation complex that includes GSK3 $\beta$ (Cervenka et al., 2011; Figure 4). This reciprocal interaction has a negative feedback loop. GSK3 $\beta$ inhibits the activation of p38 and JNK by binding the MAP3K MEKK4. It was proposed that GSK $3 \beta$ could potentially phosphorylate an $\mathrm{N}$-terminal residue of MEKK4, but this has not been proven yet (Abell et al., 2007). Another indirect negative loop has been proposed in several models: the expression of Wnt inhibitor DKK-1 relies on p38 activation, as shown in primary osteoblasts (Kamiya et al., 2010; Figure 4).

\section{Estrogen Receptors}

Estrogen receptor (ER) effects take place through the classic or genomic pathway, in which $\operatorname{ER} \alpha$ and $\operatorname{ER} \beta$ translocate to the nucleus to bind specific responsive elements on target genes. However, faster effects need signaling through PKA, PI3K and MAPK (Honda et al., 2000; Yamakawa and Arita, 2004). Accordingly, the ER pathway can activate p38, and reciprocally p38 can act on ER. p38 is stimulated by $\beta$-estradiol in human dental papilla cells, in which both proliferation and some odontoosteogenic markers are enhanced, depending on JNK and p38 (Li et al., 2014b). The activation of $\mathrm{p} 38$ by this molecule takes place through ER $\alpha$, but not ER $\beta$ (Geraldes et al., 2003; Mori-Abe et al., 2003). In contrast, in human dental pulp cells, the upregulation of OPG by estradiol is reported, and SB203580 blocks this effect. Strikingly, these actions do not seem to take place through the classic ER $\alpha$ and ER $\beta$ receptors, as their chemical agonists do not trigger downstream effects on OPG (Manokawinchoke et al., 2016). In MC3T3, saponin diosgenin acts on ER and, as a result, stimulates the production of VEGF via the interplay of $\mathrm{p} 38$, PI3K, and HIF (Yen et al., 2005). In MG-63 osteoblastic cells, $\beta$-estradiol and mechanical stress can phosphorylate ERK and p38 independently, with different kinetics. By combining both 


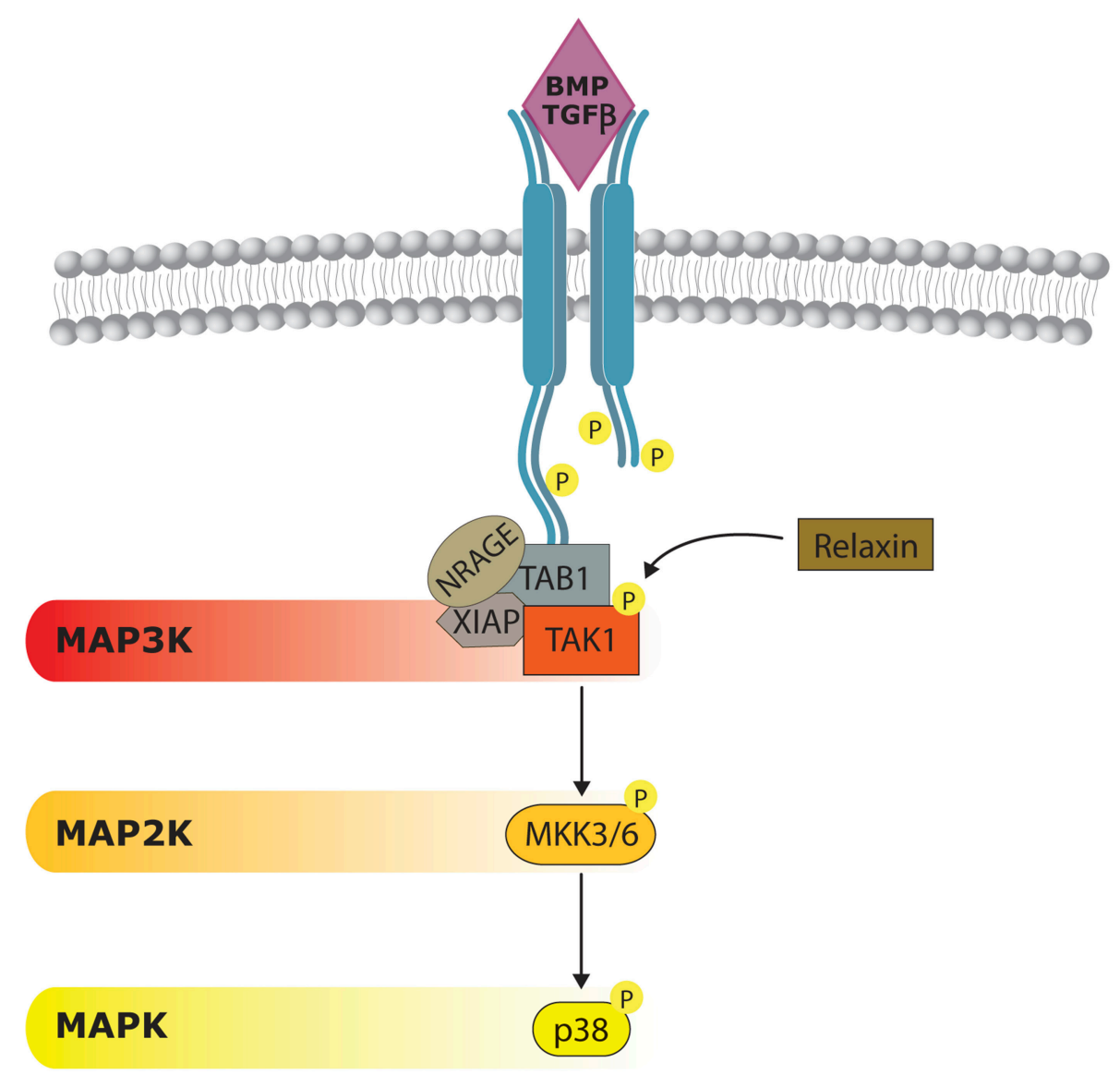

FIGURE 3 | Non-canonical BMP/TGF $\beta$ signaling. p38 activity can be triggered by a BMP-dependent mechanism. Once BMP receptors (BMPR) are stimulated they form a complex formed by NRAGE, XIAP, and TAB1, which is responsible of TAK1 activation. Relaxin can act on TAK1, cooperating on p38 activation. Although considered to be independent from SMAD activity, some cross-regulation have also been reported.

treatments, the researchers reported the synergistic expression of Ptgs2 (encoding COX2) and Fos by elevating Integrin-b1 levels (Yeh et al., 2010).

\section{PTH}

The first link of PTH with p38 in MC3T3 implicated the necessary activation of the cAMP-PKA pathway (Rey et al., 2007). The chronic or intermittent treatment of PTH on the beta-arrestin-2 (Arrb2) knockout show that the main signaling pathways implicated are p38 and NFKB (Bianchi and Ferrari, 2009). On the Mkp1 knockout, the interplay between this phosphatase, p38 and PTH was investigated. The continuous treatment of PTH leads to effects on p38 signaling by acting on the phosphatase MKP-1, negatively regulating ERK and p38 (Mahalingam et al., 2013). PTH downregulates the cell cycle and apoptosis regulatory protein 1 (CARP1) via $\mathrm{p} 38$ in osteoblastic cells (Sharma et al., 2013). p38 was also needed for COX2 stimulation by PTH in primary osteoblasts (Park et al., 2007).

The most relevant study on intermittent treatment with PTH and the role of $\mathrm{p} 38$ has been published recently. As shown with the conditional knockout Ocn-Cre; $p 38 a^{f / f}$, PTH could not exert its anabolic effects in vivo, due to a lack of p38 in mature osteoblasts. Although the authors reported that, in these animals, $\mathrm{PTH}$-induced expression of Rankl is supressed, still the net effect of $\mathrm{p} 38$ deletion is reduced ossification, due to the inability of PTH to induce osteogenic genes. In addition, the authors establish the possibility that PTH activates $\mathrm{p} 38$ through cAMP/PKA signaling (Thouverey and Caverzasio, 2015b). Mechanistically, it has been proposed that PTH increases both SMAD and p38 BMP signaling in MSCs (Yu et al., 2012).

\section{FGF, IGF-1, and VEGF}

The first hints of p38 activation by FGF2 in MC3T3 were reported in 1997, on behalf of MMP1 expression, even before any commercial pp38 antibody was available (Newberry et al., 1997). Subsequently, it was proven that FGF2 induces p38 phosphorylation in MC3T3 (Kozawa et al., 1999), and in immortalized human neonatal calvarial cells (Debiais et al., 2001). In another report, it was suggested that strontium ranelate plays a similar role in combination with FGF2. Moreover, MAPK induction is blocked by an FGF inhibitor 


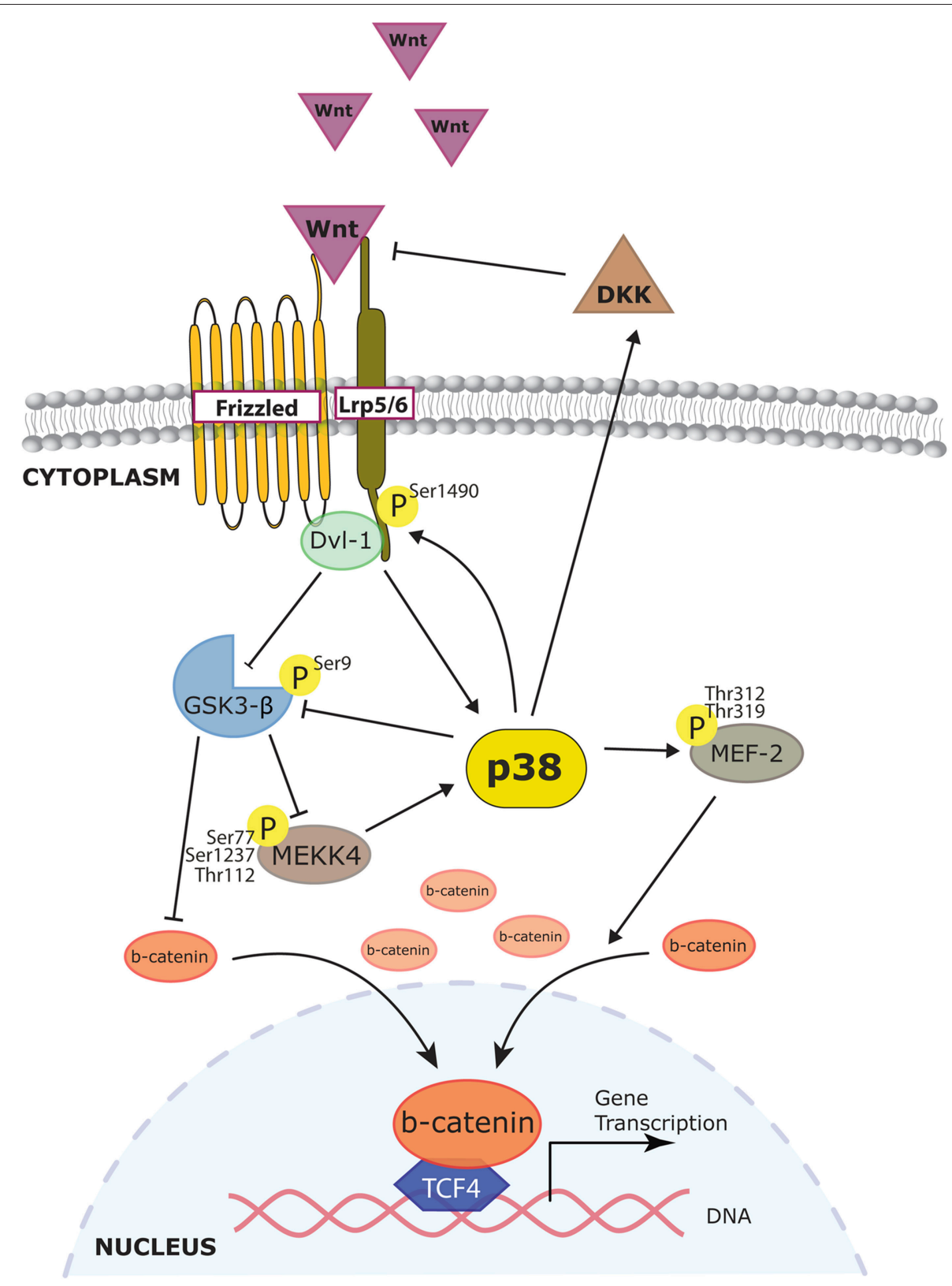

FIGURE 4 | Role of p38 MAPK in Wnt signaling. Wnt pathway activation leads to $\beta$-catenin accumulation, which enables $\beta$-catenin to translocate and initiate the transcription of target genes. p38 participates in the regulation of $\beta$-catenin accumulation by targeting different steps of the Wnt signaling. Wnt can activate p38 through Disheveled (Dvl) proteins and at the same time also inactivate GSK3 $\beta$ allowing $\beta$-catenin to accumulate. Activated p38 can reinforce GSK3 $\beta$ inhibition therefore increasing cytoplasmic $\beta$-catenin. Moreover, effects of p38 phosphorylation on MEF2 also enhance $\beta$-catenin nuclear accumulation. p38 also exerts negative effects on Wnt signaling since DKK-1 expression (a Wnt inhibitor) relies on p38 activation.

(Caverzasio and Thouverey, 2011). It should be noted that strontium ranelate alone stimulates p38 and ERK activation in $\mathrm{C} 3 \mathrm{H} 10 \mathrm{~T} 2$, inducing proliferation (Caverzasio, 2008). In human MSC, IGF-1 activates p38, JNK, and ERK. These kinases are essential to the upregulation of Osterix upon IGF-1 treatment, as this is blocked by chemical inhibitors (Celil and Campbell, 2005). Although VEGF cannot activate p38 alone in human adipose mesenchymal stem cells, it can cooperate with BMP6 signaling to direct differentiation toward osteoblastic commitment, and to avoid adipogenesis. This positive collaboration is mediated via simultaneous activation of p38 and AKT inhibition (Li et al., 2015a).

\section{AMPK/Adiponectin}

Adiponectin can activate p38 and JNK by binding to its own receptor, as AdipoR1 siRNAs block p38 phosphorylation in primary trabecular osteoblasts. Interestingly, the p38 and 
JNK cascades are independently and respectively associated with osteoblast activity and proliferation (Luo et al., 2005). Indeed, in $\mathrm{C} 3 \mathrm{H} 10 / \mathrm{T} 2$ cells, adiponectin induces osteogenic genes such as Spp1, Bglap, and Ptgs2 via p38 through AdipoR1, but not AdipoR2. Also, adiponectin favors RUNX2 and CREB recruitment to Bglap and Spp1 promoters. (Lee et al., 2009). Adiponectin is also seen as a p38 stimulus to favor $R A N K L$ transcription and at the same time inhibit $O P G$, thus leading to osteoclast activation (Luo et al., 2006). Intriguingly, regarding osteoblastogenesis, the relationship between adiponectin and p38 stimulation may generate different outputs depending on the cell type. In calcifying vascular smooth muscle cells, adiponectin p38activation is related to impairment of osteoblastic differentiation (Luo et al., 2009).

\section{Inflammatory Cytokines Interleukins}

Interleukin-1 $\beta$ (IL-1 $\beta$ ) activates p38 in MG-63 and MC3T3 cells, which helps to induce IL-6 and stabilize its mRNA (Kumar et al., 2001; Patil et al., 2004). In addition, IL-1 $\beta$ activates both ERK and p38, but not JNK, in MG-63 cells (Lambert et al., 2007). It also accelerates osteoblastic differentiation, presumably through p38 activation, as the inhibitor SB2035820 supresses primary rat osteoblasts' mineralization (Lin et al., 2011). Conversely, one report analyzed the negative impact of IL-1 $\beta$ on BMP2 osteogenesis. These effects are, at least in part, due to p38 activation by this interleukin (Huang et al., 2014). Moreover, p38 and ERK are linked to IL-1 $\beta$-induced Opg expression, therefore presumably preventing resorption (Lambert et al., 2007).

\section{Prostaglandins}

In calvarial osteoblasts, $\mathrm{PGE}_{2}$ activates p38 via EP2 and cAMP, while ERK is triggered via EP4/PKC, and JNK can be activated by both EP2 and EP4. Inactivation of each pathway results in decreased osteogenic markers (Minamizaki et al., 2009). In MC3T3, PGE $_{1}$ signaling through p38 and ERK increases VEGF synthesis and ALP activity. Moreover, the same authors suggested that in this cascade, p38 would be downstream of cAMP and PKA (Tokuda et al., 2001; Kakita et al., 2004). In the cell line MG-63, 15d-PGJ 2 (15-deoxy-delta-12,14-prostaglandin J2) independently activates $\mathrm{p} 38$ in a very rapid manner. The use of inhibitors PD169316 and PD098580 blocks 15d-PGJ -induced $_{2}$ PTGS2 transcription (Kitz et al., 2011). The same prostaglandin prevents cell death of this osteosarcoma line. The mechanism of action includes signaling via the p38/AKT/Egr-1 axis (Koyani et al., 2016).

\section{TNF $\alpha$}

$\mathrm{TNF} \alpha$ is recognized as an inductor of p38 and is implicated in IL6 synthesis in MSCs (Zhou et al., 2006) and in MC3T3 (Dai et al., 2006). Huang et al showed that TNF $\alpha$ inhibited BMP2 osteogenesis via $\mathrm{p} 38$. Chemical inhibition of $\mathrm{p} 38$ restores the expression levels of RUNX2 and other osteogenic markers triggered by BMP-2, despite the presence of TNF $\alpha$ (Huang et al., 2014). TNF $\alpha$-mediated p38 activation has also been linked to Rankl early expression, but not during the late phase (Dai et al., 2006).

\section{ECM and Adhesion \\ Rho-Kinase}

Endothelin-1 and prostaglandin- $\mathrm{F}_{2 \alpha}\left(\mathrm{PGF}_{2 \alpha}\right)$ can activate IL6 by acting both on Rho-kinase and p38 on MC3T3. The effects disappear after treatment with the Rho inhibitors fasudil or Y27632, or the p38 inhibitors SB2035820 and BIRB0796 (Minamitani et al., 2008). Thrombin can also directly activate ERK and JNK, and indirectly activate p38 through Rho-kinase. The actions on ERK and p38 lead to an increase of IL6 that can be stopped by fasudil and Y27632 (Kato et al., 2011). Fluid flow forces can also activate PI3K, ERK, and p38 via RhoA-ROCK in osteoblasts (Hamamura et al., 2012). Dr. Glimcher's group found that FGD1 signals through CDC42 to the MAP3K MLK3, which in turn activates $\mathrm{p} 38$ and ERK, provoking RUNX2 phosphorylation. Mutations in FGD1 are associated with faciogenital dysplasia (FGDY), which is characterized by skeletal defects that are comparable to the phenotype of $M l k 3^{-/-}$mice (Zou et al., 2011).

\section{Extracellular Matrix Proteins}

The extracellular matrix holds a set of molecules that can directly activate the MAPK or are needed for MAPK function. For instance, calcium, one of the main constituents of bone ECM, elevates MC3T3 proliferation via ERK and p38 activation, as its chemical blockage interrupts the proliferative effect (Yamaguchi et al., 2000). CCNs are ECM proteins that can act as growth factors and are critical for osteoblast function. CCN-1 to 6 have a positive impact on Runx2, Sp7, Colla1, Alp, and Bglap expression, partly due to activation of ERK and p38 (Kawaki et al., 2011). The expression of BMP4 induced by CCN3 depends on p38 and JNK function, as demonstrated with a chemical antagonist and dominant negative MAPK forms (Tan et al., 2012). Dentin matrix protein1 (DMP1) has been proven to serve as an inductor of differentiation for odontoblasts and osteoblasts. It was demonstrated that DMP-1 increases intracellular calcium levels in several osteoblastic cells, and stimulates phosphorylation and nuclear translocation of $\mathrm{p} 38$, which leads to activation of downstream targets such as MK2 and HSP27, and nuclear translocation of RUNX2 (Eapen et al., 2010). DDR2 (Discoidin Domain Receptor-2) is a tyrosine-kinase receptor with collagen affinity. $D d r 2$ is transcriptionally activated by ATF4 and C/EBP $\beta$, where the former is a known target of p38. At the same time, DDR2 needs p38 activity to trigger Runx2 and osteocalcin expression (Lin et al., 2010). In addition, Plexins (Plxn) are semaphorin receptors that were originally involved in cell adhesion and migration. PlxnA2 is expressed in bone, and its siRNA inhibition reduces phosphorylated levels of SMAD1, AKT, and p38, as well as Runx2 expression and mineralization. Moreover, it seems that PlxnA2 activity may be associated with binding to BMPRs (Oh et al., 2012).

\section{Stresses and Physical Inputs Chemical Stressors}

MAPKs have been traditionally described as stress kinases that can be triggered by multiple stressors. The use of certain chemical compounds was recurrent in many early in vitro experiments. For example, arsenate induces p38, and this leads to an increment 
in peroxiredoxin I protein levels in MC3T3, but does not affect its mRNA levels ( $\mathrm{Li}$ et al., 2002). Another chemical stressor, cadmium, requires p38 function to induce $\mathrm{PGE}_{2}$ in primary osteoblasts (Miyahara et al., 2004). In addition, temperature stress can also trigger p38 in MSC, which has a positive effect on their osteogenic commitment. Indeed, chemical blockage of this MAPK prevents the stimulation of proteins such as RUNX2, OPN, BSP, and collagen I (Nie et al., 2015).

\section{Hypoxia}

In MSCs, hypoxia clearly induces osteoblastic differentiation through ERK and p38 activation, particularly when they are seeded in bone-derived scaffolds (Zhou et al., 2013). Similar effects are seen in periodontal ligament cells when co-cultured with endothelial cells (Wu et al., 2013). Hypoxia has also been studied in osteoarthritic osteoblasts, where it upregulates leptin, which also involves p38 signaling (Bouvard et al., 2014).

\section{Mechanical Inputs}

Mechanical loading constantly shapes the skeleton, and some physical stimuli have been shown to activate p38 in several in vitro and in vivo experimental settings. Static stretching is an in vitro model that tries to reproduce the effects of bone distraction on osteoblasts. In this model, p38 and ERK are phosphorylated, which stimulates VEGF release in human MSCs. When these MAPKs are inhibited, VEGF is no longer activated (Kim et al., 2010). Using the same model, other authors showed effects of p38 on BMP-2 and BMP4 production, which in turn activate Col1a1, Runx2, Spp1, Alp, and Bglap in MC3T3 (Wang et al., 2012; Zhang et al., 2013). Interestingly, siRNAs against TAK1 dramatically soften this stretching activation in MC3T3, as well as IL-6 expression, which is also decreased by blocking p38 (Fukuno et al., 2011). ROS17/2.8 cells subjected to stretching or to microgravity show that inhibition of p38 by SB203580 extended the time expression of Egr1 (Granet et al., 2001). Physiologically, stretching forces also play a role in the periodontal space. Indeed, several reports show that cyclic tension activates MAPK signaling and increases osteogenesis in human periodontal ligament cell (Li et al., 2014a; Suzuki et al., 2014). In this model, p38 and ERK activation, but not JNK, are related to PTGS2 and BMP2 transcription (Suzuki et al., 2014).

Furthermore, fluid flow shear stress can also activate p38 and ERK in bone marrow stromal cells (Kreke et al., 2008) and in MG63 (Lee et al., 2008a). The activation of these MAPKs is associated with the interplay between integrins $a_{v} \beta_{3}$ and $\beta 1$ with the adaptor protein Shc. This leads to Fos, Ptgs2, and Spp1 expression (Lee et al., 2008a). Integrins can also activate p38 by contacting other molecules. In human osteosarcoma cells, angiopoietin-like protein 2 (ANGPTL2) appears to interact with integrin $\alpha_{5} \beta_{1}$ to promote $\mathrm{p} 38$ activation and MMP9 expression, which favors invasiveness (Odagiri et al., 2014). Fluid flow cell stress in MC3T3 activates ERK and p38 via Rho kinase, leading to expression of Ptgs2, Spp1, and Per2 (Hamamura et al., 2012).

\section{Ultrasound, Electric and Magnetic Fields and Lasers}

Other osteogenic stimuli that are not related to loading mechanical forces but electromagnetic waves also have osteogenic potential via p38 (Xiao et al., 2009). Ultrasounds can stimulate MAPKs in primary osteoblasts cultures and favor the expression of metalloproteinase 13 (MMP13), which increases the binding of Fos and Jun to AP-1 elements at promoter level. These effects are supressed by treatment with p38 inhibitors SB2035820 or JNK inhibitor SP600125, but not when ERK is inhibited (Chiu et al., 2008). Previously, it was shown that p38 inhibitor SB203580 prevents ultrasound-induced COX2 and osteocalcin expression in murine cells ST2 (Naruse et al., 2003). Electromagnetic stimulation increases p38, JNK, and ERK phosphorylation levels in MC3T3. Inhibition of these MAPK is related to a reduction in electromagnetically induced osteopontin, PDGF and VEGF levels (Yumoto et al., 2015). Similarly, low frequency electromagnetic fields favor collagen accumulation, probably via p38, as the use of SB203580 diminishes this effect (Soda et al., 2008). In addition, high frequency fields raise p38 mRNA levels in C3H10T2 (Teven et al., 2012). Biphasic electric current has also been applied in an in vitro osteogenic model with human stromal cells. This stimulus activates both ERK and p38 MAPK pathways, leading to increased proliferation and induction of VEGF and HIF- $\alpha$, which can be supressed by chemical inhibition (Kim et al., 2009).

\section{Pharmacological Compounds}

Bisphosphonates were found to induce ERK and p38 pathways, halt proliferation, and favor apoptosis in sarcoma cell lines (Kubo et al., 2008). Statins, therapeutic drugs to fight hypercholesterolemia, can have a positive effect on bone formation. Simvastatin induces HSP27 specifically via p38 signaling in MC3T3, and SB203580 blocks this effect (Wang et al., 2003). Generally, statins and bisphosphonates can have a dual action on bone cells: they can inhibit the ERK pathway, and accentuate p38 signaling. ERK and p38 seem to be reciprocally inhibited. The activation of p38 favors OPG overexpression, while the inhibition of ERK downregulates CD-1, RANKL, and MCSF. Thus, the net result of bisphosphonate and statin treatment would be inhibition of osteoblast-induced osteoclast maturation (Tsubaki et al., 2012). Thiazolidinediones (TZD), a drug for diabetes type 2 treatment, can also stimulate ERK and p38 via GPR40 and Ras activation. Apparently, this pathway, which is independent of PPAR $\gamma$ activity, leads to TZD-induced osteocyte apoptosis (Mieczkowska et al., 2012).

In traditional Asian medicine, a myriad of herb and plant compounds have been used historically to treat bone diseases such as osteoporosis or fractures. Many of these compounds contain remarkable doses of pro-estrogenic chemicals, antioxidants or anti-inflammatory agents, and have been linked to p38 function. Phytoestrogens (isoflavonoids) group non-steroidal compounds of plant origin that resemble human estrogens. Some of them have been studied as bone anabolic therapies, as they increment the levels of several osteogenic markers. They include genistein (which involve a p38-RUNX2), 8-prenylkaempferol, sesamin and caffeic acid 3,4-dihydroxy-phenethyl ester (CADPE) (Chiou et al., 2011; Wanachewin et al., 2012; Liao et al., 2014; Schilling et al., 2014). Another important group of natural substances is the flavonoid family. Flavonoids are present in fruit, vegetables and 
seeds, and have long been known for their beneficial effects. Naringin, ugonin K, neobavaisoflavone, puerarin, quercetin, icariin and apigenin have shown anabolic abilities in some osteogenic models both in vivo and in vitro (Ming et al., 2013; Welch and Hardcastle, 2014; Li et al., 2015b; Zhang et al., 2015; An et al., 2016). The saponins family also has proven in vitro osteogenic actions that affect both osteoblast proliferation and differentiation (Jeong et al., 2010; Niu et al., 2011; Zhou et al., 2015) and osteoclast activation (Zhou et al., 2015). Other substances, such as coumarinic compounds, have only been associated with osteoblast commitment (Tang et al., 2008). Lactone derivatives affect both p38 and ERK pathways and are linked to osteoblast function (Lee and Choi, 2011) and osteoclast impairment (Zhai et al., 2014). Isoquinolines, quinones and lignans can increase ALP activity and Bmp2 expression, as well as upstream effectors like RUNX2, in pre-osteoblasts and mesenchymal cells and in vivo models (Lee et al., 2008b; Kim et al., 2014; Moon et al., 2015; Yang et al., 2015a). In addition, phenolic compounds are associated with positive effects on osteogenesis. A diet enriched in blueberries seems to ameliorate bone marker levels and diminish bone resorption in rats. These changes are related to p38 activation and high levels of betacatenin (Chen et al., 2010). Xanthonoids in gambogic acid are linked to decreased osteoclastogenesis and bone loss (Ma et al., 2015).

\section{CONCLUDING REMARKS}

p38 MAPK plays a pivotal role in different steps of osteoblast differentiation. In vivo, p38 deletion hampers osteoblast terminal differentiation and the appearance of osteocytes, which directly affects bone composition and maintenance. Taking into account the growing number of triggers of p 38 activity and the key action of MAPK in bone development and homeostasis, we should consider p38 as a central hub for signaling convergence toward osteoblastogenesis. As seen in multiple in vitro cell-based models, p38 integrates inputs from different stimuli. The latter range

\section{REFERENCES}

Abell, A. N., Granger, D. A., and Johnson, G. L. (2007). MEKK4 stimulation of p38 and JNK activity is negatively regulated by GSK3beta. J. Biol. Chem. 282, 30476-30484. doi: 10.1074/jbc.M705783200

Alonso, G., Ambrosino, C., Jones, M., and Nebreda, A. R. (2000). Differential activation of p38 mitogen-activated protein kinase isoforms depending on signal strength. J. Biol. Chem. 275, 40641-40648. doi: 10.1074/jbc.M007835200

An, J., Yang, H., Zhang, Q., Liu, C., Zhao, J., Zhang, L., et al. (2016). Natural products for treatment of osteoporosis: the effects and mechanisms on promoting osteoblast-mediated bone formation. Life Sci. 147, 46-58. doi: 10.1016/j.lfs.2016.01.024

Aouadi, M., Jager, J., Laurent, K., Gonzalez, T., Cormont, M., Binetruy, B., et al. (2007). p38MAP Kinase activity is required for human primary adipocyte differentiation. FEBS Lett. 581, 5591-5596. doi: 10.1016/j.febslet.2007. 10.064

Aouadi, M., Laurent, K., Prot, M., Le Marchand-Brustel, Y., Binetruy, B., and Bost, F. (2006). Inhibition of p38MAPK increases adipogenesis from embryonic to adult stages. Diabetes 55, 281-289. doi: 10.2337/diabetes.55.02.06.db0 5-0963 from mechanical loading to signaling molecules like cytokines, of which BMP/TGF $\beta$ and Wnt pathways have been the most widely studied. The in vivo evidence reinforces this hypothesis. As seen in specific knockouts, deleting some key effectors of the p38-MAPK pathway affects osteoblast development at different moments during differentiation. Therefore, disturbing p38 affects a necessary integrator of various signaling inputs.

Matrix deposition and shaping is a local, fine-tuned event affected by multiple factors. We know that MAPKs such as p38, ERK, and JNK are rapidly activated, and are thus convenient for an anabolic cell like the osteoblast to respond to different local spurs. Bearing all this in mind, the p38 cascade could be a good target for anabolic bone therapies. However, the large number of activators and the different levels of selfand cross-regulation make it difficult to specifically target it therapeutically. On another front, assessing p38 activity could inform clinicians about the ability of bone to respond to anabolic therapies.

\section{AUTHOR CONTRIBUTIONS}

ER, BG, and FV conceived, analyzed and discussed the manuscript. ER and FV wrote the manuscript. ER and BG draw the figures.

\section{FUNDING}

This work was supported by grants from the MEC (BFU201456313P) and Fundació La Marató de TV3.

\section{ACKNOWLEDGMENTS}

We thank the members of the Ventura laboratory for their courageous work on this research topic. In particular, we are grateful to Arnau Ulsamer, María José Ortuño, Antonio G. Susperregui and Cristina Gamell for their valuable input prior to writing this review.

Arimoto, K., Fukuda, H., Imajoh-Ohmi, S., Saito, H., and Takekawa, M. (2008). Formation of stress granules inhibits apoptosis by suppressing stress-responsive MAPK pathways. Nat. Cell Biol. 10, 1324-1332. doi: 10.1038/ncb1791

Arnott, J. A., Zhang, X., Sanjay, A., Owen, T. A., Smock, S. L., Rehman, S., et al. (2008). Molecular requirements for induction of CTGF expression by TGFbeta1 in primary osteoblasts. Bone 42, 871-885. doi: 10.1016/j.bone.2008.01.006

Artigas, N., Ureña, C., Rodriguez-Carballo, E., Rosa, J. L., and Ventura, F. (2014). Mitogen-activated protein kinase (MAPK)-regulated interactions between Osterix and Runx2 are critical for the transcriptional osteogenic program. J. Biol. Chem. 289, 27105-27117. doi: 10.1074/jbc.M114.576793

Asada, N., Katayama, Y., Sato, M., Minagawa, K., Wakahashi, K., Kawano, H., et al. (2013). Matrix-embedded osteocytes regulate mobilization of hematopoietic stem/progenitor cells. Cell Stem Cell 12, 737-747. doi: 10.1016/j.stem.2013.05.001

Augello, A., and De Bari, C. (2010). The regulation of differentiation in mesenchymal stem cells. Hum. Gene Ther. 21, 1226-1238. doi: 10.1089/hum.2010.173

Badger, A. M., Bradbeer, J. N., Votta, B., Lee, J. C., Adams, J. L., and Griswold, D. E. (1996). Pharmacological profile of SB 203580, a selective inhibitor of cytokine suppressive binding protein/p38 kinase, in animal models of arthritis, bone 
resorption, endotoxin shock and immune function. J. Pharmacol. Exp. Ther. 279, 1453-1461.

Bain, J., Plater, L., Elliott, M., Shpiro, N., Hastie, C. J., McLauchlan, H., et al. (2007). The selectivity of protein kinase inhibitors: a further update. Biochem. J. 408, 297-315. doi: 10.1042/BJ20070797

Beardmore, V. A., Hinton, H. J., Eftychi, C., Apostolaki, M., Armaka, M., Darragh, J., et al. (2005). Generation and characterization of p38beta (MAPK11) genetargeted mice. Mol. Cell. Biol. 25, 10454-10464. doi: 10.1128/MCB.25.23.1045410464.2005

Berendsen, A. D., and Olsen, B. R. (2015). Bone development. Bone 80, 14-18. doi: 10.1016/j.bone.2015.04.035

Bermudez, O., Pagés, G., and Gimond, C. (2010). The dual-specificity MAP kinase phosphatases: critical roles in development and cancer. Am. J. Physiol. Cell Physiol. 299, C189-C202. doi: 10.1152/ajpcell.00347.2009

Bernet, J. D., Doles, J. D., Hall, J. K., Kelly Tanaka, K., Carter, T. A., and Olwin, B. B. (2014). p38 MAPK signaling underlies a cell-autonomous loss of stem cell self-renewal in skeletal muscle of aged mice. Nat. Med. 20, 265-271. doi: 10.1038/nm.3465

Bianchi, E. N., and Ferrari, S. L. (2009). Beta-arrestin2 regulates parathyroid hormone effects on a p38 MAPK and NFkappaB gene expression network in osteoblasts. Bone 45, 716-725. doi: 10.1016/j.bone.2009.06.020

Bikkavilli, R. K., Feigin, M. E., and Malbon, C. C. (2008). p38 mitogen-activated protein kinase regulates canonical Wnt-beta-catenin signaling by inactivation of GSK3beta. J. Cell Sci. 121, 3598-3607. doi: 10.1242/jcs.032854

Biver, E., Thouverey, C., Magne, D., and Caverzasio, J. (2014). Crosstalk between tyrosine kinase receptors, GSK3 and BMP2 signaling during osteoblastic differentiation of human mesenchymal stem cells. Mol. Cell. Endocrinol. 382, 120-130. doi: 10.1016/j.mce.2013.09.018

Bouvard, B., Abed, E., Yéléhé-Okouma, M., Bianchi, A., Mainard, D., Netter, P., et al. (2014). Hypoxia and vitamin D differently contribute to leptin and dickkopf-related protein 2 production in human osteoarthritic subchondral bone osteoblasts. Arthritis Res. Ther. 16:459. doi: 10.1186/s13075-0140459-3

Brancho, D., Tanaka, N., Jaeschke, A., Ventura, J. J., Kelkar, N., Tanaka, Y., et al. (2003). Mechanism of p38 MAP kinase activation in vivo. Genes Dev. 17, 1969-1978. doi: 10.1101/gad.1107303

Brien, P., Pugazhendhi, D., Woodhouse, S., Oxley, D., and Pell, J. M. (2013). p38alpha MAPK regulates adult muscle stem cell fate by restricting progenitor proliferation during postnatal growth and repair. Stem Cells 31, 1597-1610. doi: 10.1002/stem.1399

Cargnello, M., and Roux, P. P. (2011). Activation and function of the MAPKs and their substrates, the MAPK-activated protein kinases. Microbiol. Mol. Biol. Rev. 75, 50-83. doi: 10.1128/MMBR.00031-10

Caverzasio, J. (2008). Strontium ranelate promotes osteoblastic cell replication through at least two different mechanisms. Bone 42, 1131-1136. doi: 10.1016/j.bone.2008.02.010

Caverzasio, J., Higgins, L., and Ammann, P. (2008). Prevention of trabecular bone loss induced by estrogen deficiency by a selective p38alpha inhibitor. J. Bone Miner. Res. 23, 1389-1397. doi: 10.1359/jbmr.080410

Caverzasio, J., and Manen, D. (2007). Essential role of Wnt3a-mediated activation of mitogen-activated protein kinase p38 for the stimulation of alkaline phosphatase activity and matrix mineralization in C3H10T1/2 mesenchymal cells. Endocrinology 148, 5323-5330. doi: 10.1210/en.2007-0520

Caverzasio, J., and Thouverey, C. (2011). Activation of FGF receptors is a new mechanism by which strontium ranelate induces osteoblastic cell growth. Cell. Physiol. Biochem. 27, 243-250. doi: 10.1159/000327950

Celil, A. B., and Campbell, P. G. (2005). BMP-2 and insulin-like growth factorI mediate Osterix (Osx) expression in human mesenchymal stem cells via the MAPK and protein kinase D signaling pathways. J. Biol. Chem. 280, 31353-31359. doi: 10.1074/jbc.M503845200

Cervenka, I., Wolf, J., Mašek, J., Krejci, P., Wilcox, W. R., Kozubik, A., et al. (2011). Mitogen-activated protein kinases promote WNT/beta-catenin signaling via phosphorylation of LRP6. Mol. Cell. Biol. 31, 179-189. doi: 10.1128/MCB.00550-10

Chandra, A., Lan, S., Zhu, J., Siclari, V. A., and Qin, L. (2013). Epidermal growth factor receptor (EGFR) signaling promotes proliferation and survival in osteoprogenitors by increasing early growth response 2 (EGR2) expression. J. Biol. Chem. 288, 20488-20498. doi: 10.1074/jbc.M112.447250
Chen, J. R., Lazarenko, O. P., Wu, X., Kang, J., Blackburn, M. L., Shankar, K., et al. (2010). Dietary-induced serum phenolic acids promote bone growth via p38 MAPK/beta-catenin canonical Wnt signaling. J. Bone Miner. Res. 25, 2399-2411. doi: 10.1002/jbmr.137

Chiou, W. F., Lee, C. H., Liao, J. F., and Chen, C. C. (2011). 8-Prenylkaempferol accelerates osteoblast maturation through bone morphogenetic protein2/p38 pathway to activate Runx2 transcription. Life Sci. 88, 335-342. doi: 10.1016/j.lfs.2010.12.009

Chiu, Y. C., Huang, T. H., Fu, W. M., Yang, R. S., and Tang, C. H. (2008). Ultrasound stimulates MMP-13 expression through p38 and JNK pathway in osteoblasts. J. Cell. Physiol. 215, 356-365. doi: 10.1002/jcp. 21322

Choi, H. R., Kim, W. K., Kim, E. Y., Han, B. S., Min, J. K., Chi, S. W., et al. (2013). Dual-specificity phosphatase 10 controls brown adipocyte differentiation by modulating the phosphorylation of p38 mitogen-activated protein kinase. PLoS ONE 8:e72340. doi: 10.1371/journal.pone.0072340

Cuadrado, A., and Nebreda, A. R. (2010). Mechanisms and functions of p38 MAPK signalling. Biochem. J. 429, 403-417. doi: 10.1042/BJ20100323

Cuenda, A., and Cohen, P. (1999). Stress-activated protein kinase-2/p38 and a rapamycin-sensitive pathway are required for $\mathrm{C} 2 \mathrm{C} 12$ myogenesis. J. Biol. Chem. 274, 4341-4346. doi: 10.1074/jbc.274.7.4341

Cuenda, A., Rouse, J., Doza, Y. N., Meier, R., Cohen, P., Gallagher, T. F., et al. (1995). SB 203580 is a specific inhibitor of a MAP kinase homologue which is stimulated by cellular stresses and interleukin-1. FEBS Lett. 364, 229-233. doi: 10.1016/0014-5793(95)00357-F

Czaplinska, D., Turczyk, L., Grudowska, A., Mieszkowska, M., Lipinska, A. D., Skladanowski, A. C., et al. (2014). Phosphorylation of RSK2 at Tyr529 by FGFR2-p38 enhances human mammary epithelial cells migration. Biochim. Biophys. Acta 1843, 2461-2470. doi: 10.1016/j.bbamcr.2014.06.022

Dai, J. C., He, P., Chen, X., and Greenfield, E. M. (2006). TNFalpha and PTH utilize distinct mechanisms to induce IL-6 and RANKL expression with markedly different kinetics. Bone 38, 509-520. doi: 10.1016/j.bone.2005.10.007

Dallas, S. L., Rosser, J. L., Mundy, G. R., and Bonewald, L. F. (2002). Proteolysis of latent transforming growth factor-beta (TGF-beta)-binding protein-1 by osteoclasts. A cellular mechanism for release of TGF-beta from bone matrix. J. Biol. Chem. 277, 21352-21360. doi: 10.1074/jbc.M111663200

Datta, N. S., Pettway, G. J., Chen, C., Koh, A. J., and McCauley, L. K. (2007). Cyclin D1 as a target for the proliferative effects of PTH and PTHrP in early osteoblastic cells. J. Bone Miner. Res. 22, 951-964. doi: 10.1359/jbmr.070328

Debiais, F., Lemonnier, J., Hay, E., Delannoy, P., Caverzasio, J., and Marie, P. J. (2001). Fibroblast growth factor-2 (FGF-2) increases Ncadherin expression through protein kinase $\mathrm{C}$ and Src-kinase pathways in human calvaria osteoblasts. J. Cell. Biochem. 81, 68-81. doi: 10.1002/1097-4644(20010401)81:1<68::AID-JCB1024>3.0.CO;2-S

de la Croix Ndong, J., Stevens, D. M., Vignaux, G., Uppuganti, S., Perrien, D. S., Yang, X., et al. (2015). Combined MEK inhibition and BMP2 treatment promotes osteoblast differentiation and bone healing in Nf1Osx -/- mice. J. Bone Miner. Res. 30, 55-63. doi: 10.1002/jbmr.2316

de la Serna, I. L., Ohkawa, Y., Berkes, C. A., Bergstrom, D. A., Dacwag, C. S., Tapscott, S. J., et al. (2005). MyoD targets chromatin remodeling complexes to the myogenin locus prior to forming a stable DNA-bound complex. Mol. Cell. Biol. 25, 3997-4009. doi: 10.1128/MCB.25.10.3997-4009.2005

del Barco Barrantes, I., Coya, J. M., Maina, F., Arthur, J. S., and Nebreda, A. R. (2011). Genetic analysis of specific and redundant roles for p38alpha and p38beta MAPKs during mouse development. Proc. Natl. Acad. Sci. U.S.A. 108, 12764-12769. doi: 10.1073/pnas.1015013108

Dhanasekaran, D. N., Kashef, K., Lee, C. M., Xu, H., and Reddy, E. P. (2007). Scaffold proteins of MAP-kinase modules. Oncogene 26, 3185-3202. doi: 10.1038/sj.onc. 1210411

Eapen, A., Sundivakkam, P., Song, Y., Ravindran, S., Ramachandran, A., Tiruppathi, C., et al. (2010). Calcium-mediated stress kinase activation by DMP1 promotes osteoblast differentiation. J. Biol. Chem. 285, 36339-36351. doi: 10.1074/jbc.M110.145607

Ehyai, S., Dionyssiou, M. G., Gordon, J. W., Williams, D., Siu, K. W., and McDermott, J. C. (2015). A p38 mitogen-activated protein kinase-regulated myocyte enhancer factor 2-beta-catenin interaction enhances canonical Wnt signaling. Mol. Cell. Biol. 36, 330-346. doi: 10.1128/MCB.00832-15

Engelman, J. A., Berg, A. H., Lewis, R. Y., Lin, A., Lisanti, M. P., and Scherer, P. E. (1999). Constitutively active mitogen-activated protein kinase kinase 6 
(MKK6) or salicylate induces spontaneous 3T3-L1 adipogenesis. J. Biol. Chem. 274, 35630-35638. doi: 10.1074/jbc.274.50.35630

Engelman, J. A., Lisanti, M. P., and Scherer, P. E. (1998). Specific inhibitors of p38 mitogen-activated protein kinase block 3T3-L1 adipogenesis. J. Biol. Chem. 273, 32111-32120. doi: 10.1074/jbc.273.48.32111

Feng, M., Tian, L., Gan, L., Liu, Z., and Sun, C. (2014). Mark4 promotes adipogenesis and triggers apoptosis in 3T3-L1 adipocytes by activating JNK1 and inhibiting p38MAPK pathways. Biol. Cell 106, 294-307. doi: 10.1111/boc.201400004

Ferguson, B. S., Nam, H., Stephens, J. M., and Morrison, R. F. (2016). Mitogendependent regulation of DUSP1 governs ERK and p38 signaling during early 3T3-L1 adipocyte differentiation. J. Cell Physiol. 231, 1562-1574. doi: $10.1002 /$ jcp. 25248

Franceschi, R. T., Ge, C., Xiao, G., Roca, H., and Jiang, D. (2007). Transcriptional regulation of osteoblasts. Ann. N.Y. Acad. Sci. 1116, 196-207. doi: 10.1196/annals.1402.081

Franz-Odendaal, T. A., Hall, B. K., and Witten, P. E. (2006). Buried alive: how osteoblasts become osteocytes. Dev. Dyn. 235, 176-190. doi: $10.1002 /$ dvdy. 20603

Fu, X., Han, B., Cai, S., Lei, Y., Sun, T., and Sheng, Z. (2009). Migration of bone marrow-derived mesenchymal stem cells induced by tumor necrosis factoralpha and its possible role in wound healing. Wound Repair Regen. 17, 185-191. doi: 10.1111/j.1524-475X.2009.00454.x

Fuentealba, L. C., Eivers, E., Ikeda, A., Hurtado, C., Kuroda, H., Pera, E. M., et al. (2007). Integrating patterning signals: Wnt/GSK3 regulates the duration of the BMP/Smad1 signal. Cell 131, 980-993. doi: 10.1016/j.cell.2007. 09.027

Fukuno, N., Matsui, H., Kanda, Y., Suzuki, O., Matsumoto, K., Sasaki, K., et al. (2011). TGF-beta-activated kinase 1 mediates mechanical stress-induced IL-6 expression in osteoblasts. Biochem. Biophys. Res. Commun. 408, 202-207. doi: 10.1016/j.bbrc.2011.02.127

Gallea, S., Lallemand, F., Atfi, A., Rawadi, G., Ramez, V., Spinella-Jaegle, S., et al. (2001). Activation of mitogen-activated protein kinase cascades is involved in regulation of bone morphogenetic protein-2-induced osteoblast differentiation in pluripotent C2C12 cells. Bone 28, 491-498. doi: 10.1016/S8756-3282(01)00415-X

Gamell, C., Osses, N., Bartrons, R., Ruckle, T., Camps, M., Rosa, J. L., et al. (2008). BMP2 induction of actin cytoskeleton reorganization and cell migration requires PI3-kinase and Cdc42 activity. J. Cell Sci. 121, 3960-3970. doi: $10.1242 /$ jcs. 031286

Gamell, C., Susperregui, A. G., Bernard, O., Rosa, J. L., and Ventura, F. (2011). The p38/MK2/Hsp25 pathway is required for BMP-2-induced cell migration. PLoS ONE 6:e16477. doi: 10.1371/journal.pone.0016477

Gardner, S., Gross, S. M., David, L. L., Klimek, J. E., and Rotwein, P. (2015). Separating myoblast differentiation from muscle cell fusion using IGF-I and the p38 MAP kinase inhibitor SB202190. Am. J. Physiol. Cell Physiol. 309, C491-C500. doi: 10.1152/ajpcell.00184.2015

Ge, C., Xiao, G., Jiang, D., and Franceschi, R. T. (2007). Critical role of the extracellular signal-regulated kinase-MAPK pathway in osteoblast differentiation and skeletal development. J. Cell Biol. 176, 709-718. doi: $10.1083 /$ jcb.200610046

Ge, C., Xiao, G., Jiang, D., Yang, Q., Hatch, N. E., Roca, H., et al. (2009). Identification and functional characterization of ERK/MAPK phosphorylation sites in the Runx2 transcription factor. J. Biol. Chem. 284, 32533-32543. doi: 10.1074/jbc.M109.040980

Ge, C., Yang, Q., Zhao, G., Yu, H., Kirkwood, K. L., and Franceschi, R. T. (2012). Interactions between extracellular signal-regulated kinase 1/2 and p38 MAP kinase pathways in the control of RUNX2 phosphorylation and transcriptional activity. J. Bone Miner. Res. 27, 538-551. doi: 10.1002/jbmr.561

Geraldes, P., Sirois, M. G., and Tanguay, J. F. (2003). Specific contribution of estrogen receptors on mitogen-activated protein kinase pathways and vascular cell activation. Circ. Res. 93, 399-405. doi: 10.1161/01.RES.0000088640.18462.42

Granet, C., Boutahar, N., Vico, L., Alexandre, C., and Lafage-Proust, M. H. (2001). MAPK and SRC-kinases control EGR-1 and NF-kappa B inductions by changes in mechanical environment in osteoblasts. Biochem. Biophys. Res. Commun. 284, 622-631. doi: 10.1006/bbrc.2001.5023
Greenblatt, M. B., Shim, J. H., and Glimcher, L. H. (2013). Mitogen-activated protein kinase pathways in osteoblasts. Annu. Rev. Cell Dev. Biol. 29, 63-79. doi: 10.1146/annurev-cellbio-101512-122347

Greenblatt, M. B., Shim, J. H., Zou, W., Sitara, D., Schweitzer, M., Hu, D., et al. (2010). The p38 MAPK pathway is essential for skeletogenesis and bone homeostasis in mice. J. Clin. Invest. 120, 2457-2473. doi: 10.1172/JCI42285

Gregory, K. E., Ono, R. N., Charbonneau, N. L., Kuo, C. L., Keene, D. R., Bachinger, H. P., et al. (2005). The prodomain of BMP-7 targets the BMP7 complex to the extracellular matrix. J. Biol. Chem. 280, 27970-27980. doi: 10.1074/jbc.M504270200

Guicheux, J., Lemonnier, J., Ghayor, C., Suzuki, A., Palmer, G., and Caverzasio, J. (2003). Activation of p38 mitogen-activated protein kinase and c-JunNH2-terminal kinase by BMP-2 and their implication in the stimulation of osteoblastic cell differentiation. J. Bone Miner. Res. 18, 2060-2068. doi: 10.1359/jbmr.2003.18.11.2060

Hah, Y. S., Kang, H. G., Cho, H. Y., Shin, S. H., Kim, U. K., Park, B. W., et al. (2013). JNK signaling plays an important role in the effects of TNF-alpha and IL-1beta on in vitro osteoblastic differentiation of cultured human periosteal-derived cells. Mol. Biol. Rep. 40, 4869-4881. doi: 10.1007/s11033-013-2586-3

Halcsik, E., Forni, M. F., Fujita, A., Verano-Braga, T., Jensen, O. N., and Sogayar, M. C. (2013). New insights in osteogenic differentiation revealed by mass spectrometric assessment of phosphorylated substrates in murine skin mesenchymal cells. BMC Cell Biol. 14:47. doi: 10.1186/1471-2121-14-47

Hamamura, K., Swarnkar, G., Tanjung, N., Cho, E., Li, J., Na, S., et al. (2012). RhoAmediated signaling in mechanotransduction of osteoblasts. Connect. Tissue Res. 53, 398-406. doi: 10.3109/03008207.2012.671398

Hata, K., Nishimura, R., Ikeda, F., Yamashita, K., Matsubara, T., Nokubi, T., et al. (2003). Differential roles of Smad1 and p38 kinase in regulation of peroxisome proliferator-activating receptor gamma during bone morphogenetic protein 2-induced adipogenesis. Mol. Biol. Cell 14, 545-555. doi: 10.1091/mbc.E02-060356

Holleville, N., Quilhac, A., Bontoux, M., and Monsoro-Burq, A. H. (2003). BMP signals regulate Dlx5 during early avian skull development. Dev. Biol. 257, 177-189. doi: 10.1016/S0012-1606(03)00059-9

Honda, K., Sawada, H., Kihara, T., Urushitani, M., Nakamizo, T., Akaike, A., et al. (2000). Phosphatidylinositol 3-kinase mediates neuroprotection by estrogen in cultured cortical neurons. J. Neurosci. Res. 60, 321-327. doi: 10.1002/(SICI)1097-4547(20000501)60:3<321::AID-JNR6>3.0.CO;2-T

Huang, H., Song, T. J., Li, X., Hu, L., He, Q., Liu, M., et al. (2009). BMP signaling pathway is required for commitment of C3H10T1/2 pluripotent stem cells to the adipocyte lineage. Proc. Natl. Acad. Sci. U.S.A. 106, 12670-12675. doi: 10.1073/pnas.0906266106

Huang, R. L., Yuan, Y., Tu, J., Zou, G. M., and Li, Q. (2014). Opposing TNFalpha/IL-1beta- and BMP-2-activated MAPK signaling pathways converge on Runx2 to regulate BMP-2-induced osteoblastic differentiation. Cell Death Disease 5:e1187. doi: 10.1038/cddis.2014.101

Huang, Y. F., Lin, J. J., Lin, C. H., Su, Y., and Hung, S. C. (2012). c-Jun N-terminal kinase 1 negatively regulates osteoblastic differentiation induced by BMP2 via phosphorylation of Runx2 at Ser104. J. Bone Miner. Res. 27, 1093-1105. doi: 10.1002/jbmr.1548

Ikeda, K., and Takeshita, S. (2016). The role of osteoclast differentiation and function in skeletal homeostasis. J. Biochem. 159, 1-8. doi: 10.1093/jb/mvv112

Iwasaki, S., Iguchi, M., Watanabe, K., Hoshino, R., Tsujimoto, M., and Kohno, M. (1999). Specific activation of the p38 mitogen-activated protein kinase signaling pathway and induction of neurite outgrowth in PC12 cells by bone morphogenetic protein-2. J. Biol. Chem. 274, 26503-26510. doi: 10.1074/jbc.274.37.26503

Jaiswal, R. K., Jaiswal, N., Bruder, S. P., Mbalaviele, G., Marshak, D. R., and Pittenger, M. F. (2000). Adult human mesenchymal stem cell differentiation to the osteogenic or adipogenic lineage is regulated by mitogen-activated protein kinase. J. Biol. Chem. 275, 9645-9652. doi: 10.1074/jbc.275.13.9645

Jeong, H. M., Han, E. H., Jin, Y. H., Hwang, Y. P., Kim, H. G., Park, B. H., et al. (2010). Saponins from the roots of Platycodon grandiflorum stimulate osteoblast differentiation via p38 MAPK- and ERK-dependent RUNX2 activation. Food Chem. Toxicol. 48, 3362-3368. doi: 10.1016/j.fct.2010.09.005

Ji, J., Zhu, J., Hu, X., Wang, T., Zhang, X., Hou, A. J., et al. (2015). (2S)-7,4'dihydroxy-8-prenylflavan stimulates adipogenesis and glucose uptake through 
p38MAPK pathway in 3T3-L1 cells. Biochem. Biophys. Res. Commun. 460, 578-582. doi: 10.1016/j.bbrc.2015.03.072

Jones, N. C., Tyner, K. J., Nibarger, L., Stanley, H. M., Cornelison, D. D., Fedorov, Y. V., et al. (2005). The p38alpha/beta MAPK functions as a molecular switch to activate the quiescent satellite cell. J. Cell Biol. 169, 105-116. doi: $10.1083 /$ jcb. 200408066

Kakita, A., Suzuki, A., Ono, Y., Miura, Y., Itoh, M., and Oiso, Y. (2004). Possible involvement of p38 MAP kinase in prostaglandin E1-induced ALP activity in osteoblast-like cells. Prostaglandins Leukot. Essent. Fatty Acids 70, 469-474. doi: 10.1016/j.plefa.2003.09.003

Kamiya, N., Kobayashi, T., Mochida, Y., Yu, P. B., Yamauchi, M., Kronenberg, H. M., et al. (2010). Wnt inhibitors Dkk1 and Sost are downstream targets of BMP signaling through the type IA receptor (BMPRIA) in osteoblasts. J. Bone Miner. Res. 25, 200-210. doi: 10.1359/jbmr.090806

Karsenty, G., and Ferron, M. (2012). The contribution of bone to whole-organism physiology. Nature 481, 314-320. doi: 10.1038/nature10763

Kato, K., Otsuka, T., Matsushima-Nishiwaki, R., Natsume, H., Kozawa, O., and Tokuda, H. (2011). Rho-kinase regulates thrombin-stimulated interleukin-6 synthesis via p38 mitogen-activated protein kinase in osteoblasts. Int. J. Mol. Med. 28, 653-658. doi: 10.3892/ijmm.2011.747

Kawaki, H., Kubota, S., Suzuki, A., Suzuki, M., Kohsaka, K., Hoshi, K., et al. (2011). Differential roles of CCN family proteins during osteoblast differentiation: involvement of Smad and MAPK signaling pathways. Bone 49, 975-989. doi: 10.1016/j.bone.2011.06.033

Kelkar, N., Standen, C. L., and Davis, R. J. (2005). Role of the JIP4 scaffold protein in the regulation of mitogen-activated protein kinase signaling pathways. Mol. Cell. Biol. 25, 2733-2743. doi: 10.1128/MCB.25.7.2733-2743.2005

Kendall, S. E., Battelli, C., Irwin, S., Mitchell, J. G., Glackin, C. A., and Verdi, J. M. (2005). NRAGE mediates p38 activation and neural progenitor apoptosis via the bone morphogenetic protein signaling cascade. Mol. Cell. Biol. 25, 7711-7724. doi: 10.1128/MCB.25.17.7711-772 4.2005

Kim, I. S., Song, J. K., Song, Y. M., Cho, T. H., Lee, T. H., Lim, S. S., et al. (2009). Novel effect of biphasic electric current on in vitro osteogenesis and cytokine production in human mesenchymal stromal cells. Tissue Eng. Part A 15, 2411-2422. doi: 10.1089/ten.tea.2008.0554

Kim, I. S., Song, Y. M., and Hwang, S. J. (2010). Osteogenic responses of human mesenchymal stromal cells to static stretch. J. Dent. Res. 89, 1129-1134. doi: 10.1177/0022034510375283

Kim, J. Y., Cheon, Y. H., Kwak, S. C., Baek, J. M., Yoon, K. H., Lee, M. S., et al. (2014). Emodin regulates bone remodeling by inhibiting osteoclastogenesis and stimulating osteoblast formation. J. Bone Miner. Res. 29, 1541-1553. doi: 10.1002/jbmr.2183

Kitz, K., Windischhofer, W., Leis, H. J., Huber, E., Kollroser, M., and Malle, E. (2011). 15-Deoxy-Delta12,14-prostaglandin J2 induces Cox-2 expression in human osteosarcoma cells through MAPK and EGFR activation involving reactive oxygen species. Free Rad. Biol. Med. 50, 854-865. doi: 10.1016/j.freeradbiomed.2010.12.039

Klein-Nulend, J., Bakker, A. D., Bacabac, R. G., Vatsa, A., and Weinbaum, S. (2013). Mechanosensation and transduction in osteocytes. Bone 54, 182-190. doi: 10.1016/j.bone.2012. 10.013

Kocic, J., Santibañez, J. F., Krstic, A., Mojsilovic, S., Ilic, V., and Bugarski, D. (2013). Interleukin-17 modulates myoblast cell migration by inhibiting urokinase type plasminogen activator expression through p38 mitogen-activated protein kinase. Int. J. Biochem. Cell Biol. 45, 464-475. doi: 10.1016/j.biocel.2012. 11.010

Koppelman, B., Webb, H. K., Medicherla, S., Almirez, R., Feng, Y., Chavez, J. C., et al. (2008). Pharmacological properties of SD-282 - an alpha-isoform selective inhibitor for p38 MAP kinase. Pharmacology 81, 204-220. doi: $10.1159 / 000112865$

Koyani, C. N., Kitz, K., Rossmann, C., Bernhart, E., Huber, E., Trummer, C., et al. (2016). Activation of the MAPK/Akt/Nrf2-Egr1/HO-1-GCLc axis protects MG-63 osteosarcoma cells against 15d-PGJ-mediated cell death. Biochem. Pharmacol. 104, 29-41. doi: 10.1016/j.bcp.2016.01.011

Kozawa, O., Tokuda, H., Matsuno, H., and Uematsu, T. (1999). Involvement of p38 mitogen-activated protein kinase in basic fibroblast growth factor-induced interleukin-6 synthesis in osteoblasts. J. Cell. Biochem. 74, 479-485.
Kreke, M. R., Sharp, L. A., Lee, Y. W., and Goldstein, A. S. (2008). Effect of intermittent shear stress on mechanotransductive signaling and osteoblastic differentiation of bone marrow stromal cells. Tissue Eng. Part A 14, 529-537. doi: 10.1089/tea.2007.0068

Kubo, T., Shimose, S., Matsuo, T., Sakai, A., and Ochi, M. (2008). Efficacy of a nitrogen-containing bisphosphonate, minodronate, in conjunction with a p38 mitogen activated protein kinase inhibitor or doxorubicin against malignant bone tumor cells. Cancer Chemother. Pharmacol. 62, 111-116. doi: 10.1007/s00280-007-0580-y

Kumar, S., Votta, B. J., Rieman, D. J., Badger, A. M., Gowen, M., and Lee, J. C. (2001). IL-1- and TNF-induced bone resorption is mediated by p38 mitogen activated protein kinase. J. Cell. Physiol. 187, 294-303. doi: 10.1002/ jcp.1082

Lambert, C., Oury, C., Dejardin, E., Chariot, A., Piette, J., Malaise, M., et al. (2007). Further insights in the mechanisms of interleukin-1beta stimulation of osteoprotegerin in osteoblast-like cells. J. Bone Miner. Res. 22, 1350-1361. doi: 10.1359/jbmr.070508

Lee, D. Y., Yeh, C. R., Chang, S. F., Lee, P. L., Chien, S., Cheng, C. K., et al. (2008a). Integrin-mediated expression of bone formation-related genes in osteoblastlike cells in response to fluid shear stress: roles of extracellular matrix, Shc, and mitogen-activated protein kinase. J. Bone Miner. Res. 23, 1140-1149. doi: 10.1359/jbmr.080302

Lee, H. W., Kim, S. Y., Kim, A. Y., Lee, E. J., Choi, J. Y., and Kim, J. B. (2009). Adiponectin stimulates osteoblast differentiation through induction of COX2 in mesenchymal progenitor cells. Stem Cells 27, 2254-2262. doi: 10.1002/stem.144

Lee, H. W., Suh, J. H., Kim, H. N., Kim, A. Y., Park, S. Y., Shin, C. S., et al. (2008b) Berberine promotes osteoblast differentiation by Runx2 activation with p38 MAPK. J. Bone Miner. Res. 23, 1227-1237. doi: 10.1359/jbmr.080325

Lee, J. C., Laydon, J. T., McDonnell, P. C., Gallagher, T. F., Kumar, S., Green, D., et al. (1994). A protein kinase involved in the regulation of inflammatory cytokine biosynthesis. Nature 372, 739-746. doi: 10.1038/372739a0

Lee, Y. S., and Choi, E. M. (2011). Costunolide stimulates the function of osteoblastic MC3T3-E1 cells. Int. Immunopharmacol. 11, 712-718. doi: 10.1016/j.intimp.2011.01.018

Li, B., Ishii, T., Tan, C. P., Soh, J. W., and Goff, S. P. (2002). Pathways of induction of peroxiredoxin I expression in osteoblasts: roles of p38 mitogen-activated protein kinase and protein kinase C. J. Biol. Chem. 277, 12418-12422. doi: 10.1074/jbc.M111443200

Li, C. J., Madhu, V., Balian, G., Dighe, A. S., and Cui, Q. (2015a). Cross-talk between VEGF and BMP-6 pathways accelerates osteogenic differentiation of human adipose-derived stem cells. J. Cell. Physiol. 230, 2671-2682. doi: $10.1002 /$ jcp. 24983

Li, L., Han, M. X., Li, S., Xu, Y., and Wang, L. (2014a). Hypoxia regulates the proliferation and osteogenic differentiation of human periodontal ligament cells under cyclic tensile stress via mitogen-activated protein kinase pathways. J. Periodontol. 85, 498-508. doi: 10.1902/jop.2013.130048

Li, Y. P., Niu, A., and Wen, Y. (2014c). Regulation of myogenic activation of p38 MAPK by TACE-mediated TNFalpha release. Front. Cell Dev. Biol. 2:21. doi: 10.3389/fcell.2014.00021

Li, Y., Wang, J., Chen, G., Feng, S., Wang, P., Zhu, X., et al. (2015b). Quercetin promotes the osteogenic differentiation of rat mesenchymal stem cells via mitogen-activated protein kinase signaling. Exp. Ther. Med. 9, 2072-2080. doi: 10.3892/etm.2015.2388

Li, Y., Yan, M., Wang, Z., Zheng, Y., Li, J., Ma, S., et al. (2014b). 17beta-estradiol promotes the odonto/osteogenic differentiation of stem cells from apical papilla via mitogen-activated protein kinase pathway. Stem Cell Res. Ther. 5, 125. doi: $10.1186 /$ scrt515

Liao, M. H., Tai, Y. T., Cherng, Y. G., Liu, S. H., Chang, Y. A., Lin, P. I., et al. (2014). Genistein induces oestrogen receptor-alpha gene expression in osteoblasts through the activation of mitogen-activated protein kinases/NFkappaB/activator protein-1 and promotes cell mineralisation. Br. J. Nutr. 111, 55-63. doi: 10.1017/S0007114513002043

Lin, F. H., Chang, J. B., and Brigman, B. E. (2011). Role of mitogen-activated protein kinase in osteoblast differentiation. J. Orthop. Res. 29, 204-210. doi: 10.1002/jor.21222

Lin, K. L., Chou, C. H., Hsieh, S. C., Hwa, S. Y., Lee, M. T., and Wang, F. F. (2010). Transcriptional upregulation of DDR2 by ATF4 facilitates osteoblastic 
differentiation through p38 MAPK-mediated Runx2 activation. J. Bone Miner. Res. 25, 2489-2503. doi: 10.1002/jbmr.159

Liu, H., Liu, Y., Viggeswarapu, M., Zheng, Z., Titus, L., and Boden, S. D. (2011). Activation of c-Jun $\mathrm{NH}(2)$-terminal kinase 1 increases cellular responsiveness to BMP-2 and decreases binding of inhibitory Smad6 to the type 1 BMP receptor. J. Bone Miner. Res. 26, 1122-1132. doi: 10.1002/jbmr.296

Liu, L., Channavajhala, P. L., Rao, V. R., Moutsatsos, I., Wu, L., Zhang, Y., et al. (2009). Proteomic characterization of the dynamic KSR-2 interactome, a signaling scaffold complex in MAPK pathway. Biochim. Biophys. Acta 1794, 1485-1495. doi: 10.1016/j.bbapap.2009.06.016

Livingstone, C., Patel, G., and Jones, N. (1995). ATF-2 contains a phosphorylationdependent transcriptional activation domain. EMBO J. 14, 1785-1797.

Lluis, F., Ballestar, E., Suelves, M., Esteller, M., and Munoz-Canoves, P. (2005). E47 phosphorylation by $\mathrm{p} 38$ MAPK promotes $\mathrm{MyoD} / \mathrm{E} 47$ association and muscle-specific gene transcription. EMBO J. 24, 974-984. doi: 10.1038/sj.emboj. 7600528

Lluis, F., Perdiguero, E., Nebreda, A. R., and Munoz-Canoves, P. (2006). Regulation of skeletal muscle gene expression by p38 MAP kinases. Trends Cell Biol. 16, 36-44. doi: 10.1016/j.tcb.2005.11.002

Long, F. (2012). Building strong bones: molecular regulation of the osteoblast lineage. Nat. Rev. Mol. Cell Biol. 13, 27-38. doi: 10.1038/nrm3254

Long, F., and Ornitz, D. M. (2013). Development of the endochondral skeleton. Cold Spring Harb. Perspect. Biol. 5:a008334. doi: 10.1101/cshperspect.a008334

Luo, T., Matsuo-Takasaki, M., Lim, J. H., and Sargent, T. D. (2001). Differential regulation of Dlx gene expression by a BMP morphogenetic gradient. Int. J. Dev. Biol. 45, 681-684.

Luo, X. H., Guo, L. J., Xie, H., Yuan, L. Q., Wu, X. P., Zhou, H. D., et al. (2006). Adiponectin stimulates RANKL and inhibits OPG expression in human osteoblasts through the MAPK signaling pathway. J. Bone Miner. Res. 21, 1648-1656. doi: 10.1359/jbmr.060707

Luo, X. H., Guo, L. J., Yuan, L. Q., Xie, H., Zhou, H. D., Wu, X. P., et al. (2005). Adiponectin stimulates human osteoblasts proliferation and differentiation via the MAPK signaling pathway. Exp. Cell Res. 309, 99-109. doi: $10.1016 /$ j.yexcr.2005.05.021

Luo, X. H., Zhao, L. L., Yuan, L. Q., Wang, M., Xie, H., and Liao, E., Y (2009). Development of arterial calcification in adiponectin-deficient mice: adiponectin regulates arterial calcification. J. Bone Miner. Res. 24, 1461-1468. doi: 10.1359/jbmr.090227

Ma, J., Ma, Y., Liu, X., Chen, S., Liu, C., Qin, A., et al. (2015). Gambogic acid inhibits osteoclast formation and ovariectomy-induced osteoporosis by suppressing the JNK, p38 and Akt signalling pathways. Biochem. J. 469, 399-408. doi: 10.1042/BJ20150151

Maekawa, T., Jin, W., and Ishii, S. (2010). The role of ATF-2 family transcription factors in adipocyte differentiation: antiobesity effects of p38 inhibitors. Mol. Cell. Biol. 30, 613-625. doi: 10.1128/MCB.00685-09

Mahalingam, C. D., Sampathi, B. R., Sharma, S., Datta, T., Das, V., AbouSamra, A. B., et al. (2013). MKP1-dependent PTH modulation of bone matrix mineralization in female mice is osteoblast maturation stage specific and involves P-ERK and P-p38 MAPKs. J. Endocrinol. 216, 315-329. doi: 10.1530/JOE-12-0372

Manokawinchoke, J., Ritprajak, P., Osathanon, T., and Pavasant, P. (2016). Estradiol induces osteoprotegerin expression by human dental pulp cells. Odontology 104, 10-18. doi: 10.1007/s10266-014-0178-x

Matsushita, T., Chan, Y. Y., Kawanami, A., Balmes, G., Landreth, G. E., and Murakami, S. (2009). Extracellular signal-regulated kinase 1 (ERK1) and ERK2 play essential roles in osteoblast differentiation and in supporting osteoclastogenesis. Mol. Cell. Biol. 29, 5843-5857. doi: 10.1128/MCB.01 549-08

Medicherla, S., Ma, J. Y., Mangadu, R., Jiang, Y., Zhao, J. J., Almirez, R., et al. (2006). A selective p38 alpha mitogen-activated protein kinase inhibitor reverses cartilage and bone destruction in mice with collagen-induced arthritis. J. Pharmacol. Exp. Ther. 318, 132-141. doi: 10.1124/jpet.105.0 98020

Mehrotra, M., Krane, S. M., Walters, K., and Pilbeam, C. (2004). Differential regulation of platelet-derived growth factor stimulated migration and proliferation in osteoblastic cells. J. Cell. Biochem. 93, 741-752. doi: $10.1002 /$ jcb. 20138
Mieczkowska, A., Basle, M. F., Chappard, D., and Mabilleau, G. (2012). Thiazolidinediones induce osteocyte apoptosis by a $\mathrm{G}$ protein-coupled receptor 40-dependent mechanism. J. Biol. Chem. 287, 23517-23526. doi: 10.1074/jbc.M111.324814

Minamitani, C., Otsuka, T., Takai, S., Matsushima-Nishiwaki, R., Adachi, S., Hanai, Y., et al. (2008). Involvement of Rho-kinase in prostaglandin F2alphastimulated interleukin- 6 synthesis via p38 mitogen-activated protein kinase in osteoblasts. Mol. Cell. Endocrinol. 291, 27-32. doi: 10.1016/j.mce.2008.05.011

Minamizaki, T., Yoshiko, Y., Kozai, K., Aubin, J. E., and Maeda, N. (2009). EP2 and EP4 receptors differentially mediate MAPK pathways underlying anabolic actions of prostaglandin $\mathrm{E} 2$ on bone formation in rat calvaria cell cultures. Bone 44, 1177-1185. doi: 10.1016/j.bone.2009.02.010

Ming, L. G., Chen, K. M., and Xian, C. J. (2013). Functions and action mechanisms of flavonoids genistein and icariin in regulating bone remodeling. J. Cell. Physiol. 228, 513-521. doi: 10.1002/jcp.24158

Miyahara, T., Katoh, T., Watanabe, M., Mikami, Y., Uchida, S., Hosoe, M., et al. (2004). Involvement of mitogen-activated protein kinases and protein kinase $\mathrm{C}$ in cadmium-induced prostaglandin $\mathrm{E} 2$ production in primary mouse osteoblastic cells. Toxicology 200, 159-167. doi: 10.1016/j.tox.2004.03.014

Miyama, K., Yamada, G., Yamamoto, T. S., Takagi, C., Miyado, K., Sakai, M., et al. (1999). A BMP-inducible gene, dlx5, regulates osteoblast differentiation and mesoderm induction. Dev. Biol. 208, 123-133. doi: 10.1006/dbio.1998.9197

Moon, J. S., Kim, S. H., Oh, S. H., Jeong, Y. W., Kang, J. H., Park, J. C., et al. (2014). Relaxin augments BMP-2-induced osteoblast differentiation and bone formation. J. Bone Miner. Res. 29, 1586-1596. doi: 10.1002/jbmr.2197

Moon, S. H., Choi, S. W., Park, S. J., Ryu, S. Y., Hwang, K. S., Kim, C. H., et al. (2015). In vitro and in vivo bone-forming activity of saururus chinensis extract. Phytother. Res. 29, 1073-1080. doi: 10.1002/ptr.5349

Mori-Abe, A., Tsutsumi, S., Takahashi, K., Toya, M., Yoshida, M., Du, B., et al. (2003). Estrogen and raloxifene induce apoptosis by activating p38 mitogenactivated protein kinase cascade in synthetic vascular smooth muscle cells. $J$. Endocrinol. 178, 417-426. doi: 10.1677/joe.0.1780417

Nam, T. W., Yoo, C. I., Kim, H. T., Kwon, C. H., Park, J. Y., and Kim, Y. K. (2008). The flavonoid quercetin induces apoptosis and inhibits migration through a MAPK-dependent mechanism in osteoblasts. J. Bone Miner. Metab. 26, 551-560. doi: 10.1007/s00774-008-0864-2

Naruse, K., Miyauchi, A., Itoman, M., and Mikuni-Takagaki, Y. (2003). Distinct anabolic response of osteoblast to low-intensity pulsed ultrasound. J. Bone Miner. Res. 18, 360-369. doi: 10.1359/jbmr.2003.18.2.360

Newberry, E. P., Willis, D., Latifi, T., Boudreaux, J. M., and Towler, D. A. (1997). Fibroblast growth factor receptor signaling activates the human interstitial collagenase promoter via the bipartite Ets-AP1 element. Mol. Endocrinol. 11, 1129-1144. doi: 10.1210/mend.11.8.9958

Nie, Y., Yan, Z., Yan, W., Xia, Q., and Zhang, Y. (2015). Cold exposure stimulates lipid metabolism, induces inflammatory response in the adipose tissue of mice and promotes the osteogenic differentiation of BMMSCs via the p38 MAPK pathway in vitro. Int. J. Clin. Exp. Pathol. 8, 10875-10886.

Niu, Y., Li, Y., Huang, H., Kong, X., Zhang, R., Liu, L., et al. (2011). Asperosaponin, V. I., a saponin component from Dipsacus asper wall, induces osteoblast differentiation through bone morphogenetic protein-2/p38 and extracellular signal-regulated kinase 1/2 pathway. Phytother. Res. 25, 1700-1706. doi: $10.1002 /$ ptr.3414

Noth, U., Tuli, R., Seghatoleslami, R., Howard, M., Shah, A., Hall, D. J., et al. (2003). Activation of p38 and Smads mediates BMP-2 effects on human trabecular bone-derived osteoblasts. Exp. Cell Res. 291, 201-211. doi: 10.1016/S00144827(03)00386-0

O’Brien, C. A., Nakashima, T., and Takayanagi, H. (2013). Osteocyte control of osteoclastogenesis. Bone 54, 258-263. doi: 10.1016/j.bone.2012.08.121

O'Callaghan, C., Fanning, L. J., Houston, A., and Barry, O. P. (2013). Loss of p38delta mitogen-activated protein kinase expression promotes oesophageal squamous cell carcinoma proliferation, migration and anchorage-independent growth. Int. J. Oncol. 43, 405-415. doi: 10.3892/ijo.2013.1968

Odagiri, H., Kadomatsu, T., Endo, M., Masuda, T., Morioka, M. S., Fukuhara, S., et al. (2014). The secreted protein ANGPTL2 promotes metastasis of osteosarcoma cells through integrin alpha5betal, p38 MAPK, and matrix metalloproteinases. Sci Signal 7:ra7. doi: 10.1126/scisignal. 2004612 
Oh, J. E., Kim, H. J., Kim, W. S., Lee, Z. H., Ryoo, H. M., Hwang, S. J., et al. (2012). PlexinA2 mediates osteoblast differentiation via regulation of Runx2. J. Bone Miner. Res. 27, 552-562. doi: 10.1002/jbmr.1471

Ortuno, M. J., Ruiz-Gaspa, S., Rodriguez-Carballo, E., Susperregui, A. R., Bartrons, R., Rosa, J. L., et al. (2010). p38 regulates expression of osteoblast-specific genes by phosphorylation of osterix. J. Biol. Chem. 285, 31985-31994. doi: 10.1074/jbc.M110.123612

Ortuno, M. J., Susperregui, A. R., Artigas, N., Rosa, J. L., and Ventura, F. (2013). Osterix induces Colla1 gene expression through binding to Sp1 sites in the bone enhancer and proximal promoter regions. Bone 52, 548-556. doi: 10.1016/j.bone.2012.11.007

Paic, F., Igwe, J. C., Nori, R., Kronenberg, M. S., Franceschetti, T., Harrington, P., et al. (2009). Identification of differentially expressed genes between osteoblasts and osteocytes. Bone 45, 682-692. doi: 10.1016/j.bone.2009.06.010

Park, H., Young Lee, S., Lee, D. S., and Yim, M. (2007). Phosphodiesterase 4 inhibitor regulates the TRANCE/OPG ratio via COX-2 expression in a manner similar to PTH in osteoblasts. Biochem. Biophys. Res. Commun. 354, 178-183. doi: 10.1016/j.bbrc.2006.12.174

Parreno, J., and Hart, D. A. (2009). Molecular and mechano-biology of collagen gel contraction mediated by human MG-63 cells: involvement of specific intracellular signaling pathways and the cytoskeleton. Biochem. Cell Biol. 87, 895-904. doi: 10.1139/O09-052

Patil, C., Zhu, X., Rossa, C. Jr., Kim, Y. J., and Kirkwood, K. L. (2004). p38 MAPK regulates IL-1beta induced IL-6 expression through mRNA stability in osteoblasts. Immunol. Invest. 33, 213-233. doi: 10.1081/IMM-120034231

Percival, C. J., and Richtsmeier, J. T. (2013). Angiogenesis and intramembranous osteogenesis. Dev. Dyn. 242, 909-922. doi: 10.1002/dvdy.23992

Puri, P. L., Wu, Z., Zhang, P., Wood, L. D., Bhakta, K. S., Han, J., et al. (2000). Induction of terminal differentiation by constitutive activation of p38 MAP kinase in human rhabdomyosarcoma cells. Genes Dev. 14, 574-584.

Qi, X., Li, T. G., Hao, J., Hu, J., Wang, J., Simmons, H., et al. (2004). BMP4 supports self-renewal of embryonic stem cells by inhibiting mitogen-activated protein kinase pathways. Proc. Natl. Acad. Sci. U.S.A. 101, 6027-6032. doi: 10.1073/pnas.0401367101

Raingeaud, J., Gupta, S., Rogers, J. S., Dickens, M., Han, J., Ulevitch, R. J., et al. (1995). Pro-inflammatory cytokines and environmental stress cause p38 mitogen-activated protein kinase activation by dual phosphorylation on tyrosine and threonine. J. Biol. Chem. 270, 7420-7426. doi: 10.1074/jbc.270.13.7420

Remy, G., Risco, A. M., Inesta-Vaquera, F. A., Gonzalez-Teran, B., Sabio, G., Davis, R. J., et al. (2010). Differential activation of p38MAPK isoforms by MKK6 and MKK3. Cell. Signal. 22, 660-667. doi: 10.1016/j.cellsig.2009.11.020

Rey, A., Manen, D., Rizzoli, R., Ferrari, S. L., and Caverzasio, J. (2007). Evidences for a role of p38 MAP kinase in the stimulation of alkaline phosphatase and matrix mineralization induced by parathyroid hormone in osteoblastic cells. Bone 41, 59-67. doi: 10.1016/j.bone.2007.02.031

Rochefort, G. Y., Pallu, S., and Benhamou, C. L. (2010). Osteocyte: the unrecognized side of bone tissue. Osteoporos. Int. 21, 1457-1469. doi: 10.1007/s00198-010-1194-5

Rodriguez-Carballo, E., Gamez, B., Mendez-Lucas, A., Sanchez-Freutrie, M., Zorzano, A., Bartrons, R., et al. (2015). p38alpha function in osteoblasts influences adipose tissue homeostasis. FASEB J. 29, 1414-1425. doi: 10.1096/fj.14-261891

Rodriguez-Carballo, E., Gamez, B., Sedo-Cabezon, L., Sanchez-Feutrie, M., Zorzano, A., Manzanares-Cespedes, C., et al. (2014). The p38alpha MAPK function in osteoprecursors is required for bone formation and bone homeostasis in adult mice. PLOS ONE 9:e102032. doi: 10.1371/journal.pone.0102032

Rodriguez-Carballo, E., Ulsamer, A., Susperregui, A. R., Manzanares-Cespedes, C., Sanchez-Garcia, E., Bartrons, R., et al. (2011). Conserved regulatory motifs in osteogenic gene promoters integrate cooperative effects of canonical Wnt and BMP pathways. J. Bone Miner. Res. 26, 718-729. doi: 10.1002/jbmr.260

Rousseau, S., Houle, F., Landry, J., and Huot, J. (1997). p38 MAP kinase activation by vascular endothelial growth factor mediates actin reorganization and cell migration in human endothelial cells. Oncogene 15, 2169-2177. doi: 10.1038/sj.onc. 1201380

Ryu, C. H., Park, S. A., Kim, S. M., Lim, J. Y., Jeong, C. H., Jun, J. A., et al. (2010). Migration of human umbilical cord blood mesenchymal stem cells mediated by stromal cell-derived factor-1/CXCR4 axis via Akt, ERK, and p38 signal transduction pathways. Biochem. Biophys. Res. Commun. 398, 105-110. doi: 10.1016/j.bbrc.2010.06.043

Sabio, G., Arthur, J. S., Kuma, Y., Peggie, M., Carr, J., Murray-Tait, V., et al. (2005). p38gamma regulates the localisation of SAP97 in the cytoskeleton by modulating its interaction with GKAP. EMBO J. 24, 1134-1145. doi: 10.1038/sj.emboj.7600578

Schilling, T., Ebert, R., Raaijmakers, N., Schütze, N., and Jakob, F. (2014). Effects of phytoestrogens and other plant-derived compounds on mesenchymal stem cells, bone maintenance and regeneration. J. Steroid Biochem. Mol. Biol. 139, 252-261. doi: 10.1016/j.jsbmb.2012.12.006

Schindler, E. M., Hindes, A., Gribben, E. L., Burns, C. J., Yin, Y., Lin, M. H., et al. (2009). p38delta Mitogen-activated protein kinase is essential for skin tumor development in mice. Cancer Res. 69, 4648-4655. doi: 10.1158/00085472.CAN-08-4455

Sciandra, M., Marino, M. T., Manara, M. C., Guerzoni, C., Grano, M., Oranger, A., et al. (2014). CD99 drives terminal differentiation of osteosarcoma cells by acting as a spatial regulator of ERK 1/2. J. Bone Miner. Res. 29, 1295-1309. doi: $10.1002 /$ jbmr.2141

Selvamurugan, N., Kwok, S., Alliston, T., Reiss, M., and Partridge, N. C. (2004). Transforming growth factor-beta 1 regulation of collagenase- 3 expression in osteoblastic cells by cross-talk between the Smad and MAPK signaling pathways and their components, Smad2 and Runx2. J. Biol. Chem. 279, 19327-19334. doi: 10.1074/jbc.M314048200

Sharma, S., Mahalingam, C. D., Das, V., Jamal, S., Levi, E., Rishi, A. K., et al. (2013). Cell cycle and apoptosis regulatory protein (CARP)- 1 is expressed in osteoblasts and regulated by PTH. Biochem. Biophys. Res. Commun. 436, 607-612. doi: 10.1016/j.bbrc.2013.05.136

Siebel, A., Cubillos-Rojas, M., Santos, R. C., Schneider, T., Bonan, C. D., Bartrons, R., et al. (2013). Contribution of S6K1/MAPK signaling pathways in the response to oxidative stress: activation of RSK and MSK by hydrogen peroxide. PLoS ONE 8:e75523. doi: 10.1371/journal.pone.0075523

Sierra, J., Villagra, A., Paredes, R., Cruzat, F., Gutierrez, S., Javed, A., et al. (2003). Regulation of the bone-specific osteocalcin gene by p300 requires Runx2/Cbfa1 and the vitamin D3 receptor but not p300 intrinsic histone acetyltransferase activity. Mol. Cell. Biol. 23, 3339-3351. doi: 10.1128/MCB.23.9.3339-3 351.2003

Simone, C., Forcales, S. V., Hill, D. A., Imbalzano, A. N., Latella, L., and Puri, P. L. (2004). p38 pathway targets SWI-SNF chromatin-remodeling complex to muscle-specific loci. Nat. Genet. 36, 738-743. doi: 10.1038/ng1378

Simonet, W. S., Lacey, D. L., Dunstan, C. R., Kelley, M., Chang, M. S., Luthy, R., et al. (1997). Osteoprotegerin: a novel secreted protein involved in the regulation of bone density. Cell 89, 309-319. doi: 10.1016/S00928674(00)80209-3

Soda, A., Ikehara, T., Kinouchi, Y., and Yoshizaki, K. (2008). Effect of exposure to an extremely low frequency-electromagnetic field on the cellular collagen with respect to signaling pathways in osteoblast-like cells. J. Med. Invest. 55, 267-278. doi: $10.2152 /$ jmi. 55.267

Son, M. J., Kim, W. K., Kwak, M., Oh, K. J., Chang, W. S., Min, J. K., et al. (2015). Silica nanoparticles inhibit brown adipocyte differentiation via regulation of p38 phosphorylation. Nanotechnology 26:435101. doi: 10.1088/0957-4484/26/43/435101

Sorrentino, A., Thakur, N., Grimsby, S., Marcusson, A., von Bulow, V., Schuster, N., et al. (2008). The type I TGF-beta receptor engages TRAF6 to activate TAK1 in a receptor kinase-independent manner. Nat. Cell Biol. 10, 1199-1207. doi: 10.1038/ncb1780

Sumara, G., Formentini, I., Collins, S., Sumara, I., Windak, R., Bodenmiller, B., et al. (2009). Regulation of PKD by the MAPK p38delta in insulin secretion and glucose homeostasis. Cell 136, 235-248. doi: 10.1016/j.cell.2008. 11.018

Suzuki, A., Guicheux, J., Palmer, G., Miura, Y., Oiso, Y., Bonjour, J. P., et al. (2002). Evidence for a role of p38 MAP kinase in expression of alkaline phosphatase during osteoblastic cell differentiation. Bone 30, 91-98. doi: 10.1016/S87563282(01)00660-3

Suzuki, A., Palmer, G., Bonjour, J. P., and Caverzasio, J. (1999). Regulation of alkaline phosphatase activity by 38 MAP kinase in response to activation of Gi protein-coupled receptors by epinephrine in osteoblast-like cells. Endocrinology 140, 3177-3182. doi: 10.1210/en.140.7.3177 
Suzuki, R., Nemoto, E., and Shimauchi, H. (2014). Cyclic tensile force up-regulates BMP-2 expression through MAP kinase and COX-2/PGE2 signaling pathways in human periodontal ligament cells. Exp. Cell Res. 323, 232-241. doi: 10.1016/j.yexcr.2014.02.013

Tan, T. W., Huang, Y. L., Chang, J. T., Lin, J. J., Fong, Y. C., Kuo, C. C., et al. (2012). CCN3 increases BMP-4 expression and bone mineralization in osteoblasts. J. Cell. Physiol. 227, 2531-2541. doi: 10.1002/jcp.22991

Tanaka, T., Iino, M., and Goto, K. (2014). Knockdown of Sec8 enhances the binding affinity of c-Jun $\mathrm{N}$-terminal kinase (JNK)-interacting protein 4 for mitogen-activated protein kinase kinase 4 (MKK4) and suppresses the phosphorylation of MKK4, p38, and JNK, thereby inhibiting apoptosis. FEBS J. 281, 5237-5250. doi: 10.1111/febs.13063

Tang, C. H., Yang, R. S., Chien, M. Y., Chen, C. C., and Fu, W. M. (2008). Enhancement of bone morphogenetic protein-2 expression and bone formation by coumarin derivatives via p38 and ERK-dependent pathway in osteoblasts. Eur. J. Pharmacol. 579, 40-49. doi: 10.1016/j.ejphar.2007.10.013

Teven, C. M., Greives, M., Natale, R. B., Su, Y., Luo, Q., He, B. C., et al. (2012). Differentiation of osteoprogenitor cells is induced by highfrequency pulsed electromagnetic fields. J. Craniofac. Surg. 23, 586-593. doi: 10.1097/SCS.0b013e31824cd6de

Thouverey, C., and Caverzasio, J. (2012). The p38alpha MAPK positively regulates osteoblast function and postnatal bone acquisition. Cell. Mol. Life Sci. 69, 3115-3125. doi: 10.1007/s00018-012-0983-8

Thouverey, C., and Caverzasio, J. (2015a). Focus on the p38 MAPK signaling pathway in bone development and maintenance. Bonekey Rep. 4, 711. doi: 10.1038/bonekey.2015.80

Thouverey, C., and Caverzasio, J. (2015b). Suppression of p38a MAPK signaling in osteoblast lineage cells impairs bone anabolic action of parathyroid hormone. J. Bone Miner. Res. doi: 10.1002/jbmr.2762. [Epub ahead of print].

Tokuda, H., Hatakeyama, D., Akamatsu, S., Tanabe, K., Yoshida, M., Shibata, T., et al. (2003). Involvement of MAP kinases in TGF-beta-stimulated vascular endothelial growth factor synthesis in osteoblasts. Arch. Biochem. Biophys. 415, 117-125. doi: 10.1016/S0003-9861(03)00225-X

Tokuda, H., Kozawa, O., Miwa, M., and Uematsu, T. (2001). p38 mitogenactivated protein (MAP) kinase but not p44/p42 MAP kinase is involved in prostaglandin E1-induced vascular endothelial growth factor synthesis in osteoblasts. J. Endocrinol. 170, 629-638. doi: 10.1677/joe.0.1700629

Troy, A., Cadwallader, A. B., Fedorov, Y., Tyner, K., Tanaka, K. K., and Olwin, B. B. (2012). Coordination of satellite cell activation and self-renewal by Parcomplex-dependent asymmetric activation of p38alpha/beta MAPK. Cell Stem Cell 11, 541-553. doi: 10.1016/j.stem.2012.05.025

Tsubaki, M., Satou, T., Itoh, T., Imano, M., Yanae, M., Kato, C., et al. (2012). Bisphosphonate- and statin-induced enhancement of OPG expression and inhibition of CD9, M-CSF, and RANKL expressions via inhibition of the Ras/MEK/ERK pathway and activation of p38MAPK in mouse bone marrow stromal cell line ST2. Mol. Cell. Endocrinol. 361, 219-231. doi: 10.1016/j.mce.2012.05.002

Ulsamer, A., Ortuño, M. J., Ruiz, S., Susperregui, A. R., Osses, N., Rosa, J. L., et al. (2008). BMP-2 induces Osterix expression through up-regulation of Dlx 5 and its phosphorylation by p38. J. Biol. Chem. 283, 3816-3826. doi: 10.1074/jbc.M704724200

van Bezooijen, R. L., ten Dijke, P., Papapoulos, S. E., and Lowik, C. W. (2005). SOST/sclerostin, an osteocyte-derived negative regulator of bone formation. Cytokine Growth Factor Rev. 16, 319-327. doi: 10.1016/j.cytogfr.2005.02.005

Viñals, F., López-Rovira, T., Rosa, J. L., and Ventura, F. (2002). Inhibition of $\mathrm{PI} 3 \mathrm{~K} / \mathrm{p} 70 \mathrm{~S} 6 \mathrm{~K}$ and $\mathrm{p} 38$ MAPK cascades increases osteoblastic differentiation induced by BMP-2. FEBS Lett. 510, 99-104. doi: 10.1016/S0014-5793(01) 03236-7

Waas, W. F., Lo, H. H., and Dalby, K. N. (2001). The kinetic mechanism of the dual phosphorylation of the ATF2 transcription factor by p38 mitogen-activated protein (MAP) kinase alpha. Implications for signal/response profiles of MAP kinase pathways. J. Biol. Chem. 276, 5676-5684. doi: 10.1074/jbc.M0087 87200

Wan, Y., Xue, R., Wang, Y., Zhang, Q., Huang, S., Wu, W., et al. (2015). The effect of neuropeptide $\mathrm{Y}$ on brown-like adipocyte's differentiation and activation. Peptides 63, 126-133. doi: 10.1016/j.peptides.2014.10.018

Wanachewin, O., Boonmaleerat, K., Pothacharoen, P., Reutrakul, V., and Kongtawelert, P. (2012). Sesamin stimulates osteoblast differentiation through p38 and ERK1/2 MAPK signaling pathways. BMC Complement. Altern. Med. 12:71. doi: $10.1186 / 1472-6882-12-71$

Wang, L., Li, J. Y., Zhang, X. Z., Liu, L., Wan, Z. M., Li, R. X., et al. (2012). Involvement of p38MAPK/NF-kappaB signaling pathways in osteoblasts differentiation in response to mechanical stretch. Ann. Biomed. Eng. 40, 1884-1894. doi: 10.1007/s10439-012-0548-x

Wang, X., Tokuda, H., Hatakeyama, D., Hirade, K., Niwa, M., Ito, H., et al. (2003). Mechanism of simvastatin on induction of heat shock protein in osteoblasts. Arch. Biochem. Biophys. 415, 6-13. doi: 10.1016/S0003-9861(03)00213-3

Wang, X. Z., and Ron, D. (1996). Stress-induced phosphorylation and activation of the transcription factor CHOP (GADD153) by p38 MAP Kinase. Science 272, 1347-1349. doi: $10.1126 /$ science. 272.5266 .1347

Welch, A. A., and Hardcastle, A. C. (2014). The effects of flavonoids on bone. Curr. Osteoporos. Rep. 12, 205-210. doi: 10.1007/s11914-014-0212-5

Wood, C. D., Thornton, T. M., Sabio, G., Davis, R. A., and Rincon, M. (2009). Nuclear localization of p38 MAPK in response to DNA damage. Int. J. Biol. Sci. 5, 428-437. doi: 10.7150/ijbs.5.428

Wu, Y., Cao, H., Yang, Y., Zhou, Y., Gu, Y., Zhao, X., et al. (2013). Effects of vascular endothelial cells on osteogenic differentiation of noncontact cocultured periodontal ligament stem cells under hypoxia. J. Periodont. Res. 48, 52-65. doi: 10.1111/j.1600-0765.2012.01503.x

Wu, Z., Woodring, P. J., Bhakta, K. S., Tamura, K., Wen, F., Feramisco, J. R., et al. (2000). p38 and extracellular signal-regulated kinases regulate the myogenic program at multiple steps. Mol. Cell. Biol. 20, 3951-3964. doi: 10.1128/MCB.20.11.3951-3964.2000

Xiao, G., Gopalakrishnan, R., Jiang, D., Reith, E., Benson, M. D., and Franceschi, R. T. (2002a). Bone morphogenetic proteins, extracellular matrix, and mitogenactivated protein kinase signaling pathways are required for osteoblast-specific gene expression and differentiation in MC3T3-E1 cells. J. Bone Miner. Res. 17, 101-110. doi: 10.1359/jbmr.2002.17.1.101

Xiao, G., Jiang, D., Gopalakrishnan, R., and Franceschi, R. T. (2002b). Fibroblast growth factor 2 induction of the osteocalcin gene requires MAPK activity and phosphorylation of the osteoblast transcription factor, Cbfa1/Runx2. J. Biol. Chem. 277, 36181-36187. doi: 10.1074/jbc.M206057200

Xiao, G., Jiang, D., Thomas, P., Benson, M. D., Guan, K., Karsenty, G., et al. (2000). MAPK pathways activate and phosphorylate the osteoblastspecific transcription factor, Cbfa1. J. Biol. Chem. 275, 4453-4459. doi: $10.1074 /$ jbc.275.6.4453

Xiao, M., Inal, C. E., Parekh, V. I., Li, X. H., and Whitnall, M. H. (2009). Role of NF-kappaB in hematopoietic niche function of osteoblasts after radiation injury. Exp. Hematol. 37, 52-64. doi: 10.1016/j.exphem.2008.09.001

$\mathrm{Xu}, \mathrm{H}$., Zhang, J., Wu, J., Guan, Y., Weng, Y., and Shang, P. (2012). Oscillatory fluid flow elicits changes in morphology, cytoskeleton and integrin-associated molecules in MLO-Y4 cells, but not in MC3T3-E1 cells. Biol. Res. 45, 163-169. doi: 10.4067/S0716-97602012000200008

Yamaguchi, K., Nagai, S., Ninomiya-Tsuji, J., Nishita, M., Tamai, K., Irie, K., et al. (1999). XIAP, a cellular member of the inhibitor of apoptosis protein family, links the receptors to TAB1-TAK1 in the BMP signaling pathway. EMBO J. 18, 179-187. doi: 10.1093/emboj/18.1.179

Yamaguchi, T., Chattopadhyay, N., Kifor, O., Sanders, J. L., and Brown, E. M. (2000). Activation of p $42 / 44$ and p38 mitogen-activated protein kinases by extracellular calcium-sensing receptor agonists induces mitogenic responses in the mouse osteoblastic MC3T3-E1 cell line. Biochem. Biophys. Res. Commun. 279, 363-368. doi: 10.1006/bbrc.2000.3955

Yamakawa, K., and Arita, J. (2004). Cross-talk between the estrogen receptor-, protein kinase A-, and mitogen-activated protein kinase-mediated signaling pathways in the regulation of lactotroph proliferation in primary culture. $J$. Steroid Biochem. Mol. Biol. 88, 123-130. doi: 10.1016/j.jsbmb.2003.11.003

Yamashita, M., Fatyol, K., Jin, C., Wang, X., Liu, Z., and Zhang, Y. E. (2008). TRAF6 mediates Smad-independent activation of JNK and p38 by TGF-beta. Mol. Cell 31, 918-924. doi: 10.1016/j.molcel.2008.09.002

Yan, J., Gan, L., Chen, D., and Sun, C. (2013). Adiponectin impairs chicken preadipocytes differentiation through p38 MAPK/ATF-2 and TOR/p70 S6 kinase pathways. PLoS ONE 8:e77716. doi: 10.1371/journal.pone.0077716

Yang, B., Lin, X., Yang, C., Tan, J., Li, W., and Kuang, H. (2015a). Sambucus williamsii hance promotes MC3T3-E1 cells proliferation and differentiation via BMP-2/Smad/p38/JNK/Runx2 signaling pathway. Phytother. Res. 29, 1692-1699. doi: 10.1002/ptr.5482 
Yang, G., Yuan, G., Li, X., Liu, P., Chen, Z., and Fan, M. (2014). BMP-2 induction of Dlx3 expression is mediated by $\mathrm{p} 38 / \mathrm{Smad} 5$ signaling pathway in osteoblastic MC3T3-E1 cells. J. Cell. Physiol. 229, 943-954. doi: 10.1002/jcp.24525

Yang, J., Ye, L., Hui, T. Q., Yang, D. M., Huang, D. M., Zhou, X. D., et al. (2015b). Bone morphogenetic protein 2-induced human dental pulp cell differentiation involves p38 mitogen-activated protein kinase-activated canonical WNT pathway. Int. J. Oral Sci. 7, 95-102. doi: 10.1038/ijos.2015.7

Yang, T. T., Xiong, Q., Enslen, H., Davis, R. J., and Chow, C. W. (2002). Phosphorylation of NFATc4 by p38 mitogen-activated protein kinases. Mol. Cell. Biol. 22, 3892-3904. doi: 10.1128/MCB.22.11.3892-3904.2002

Yang, X., Matsuda, K., Bialek, P., Jacquot, S., Masuoka, H. C., Schinke, T., et al. (2004). ATF4 is a substrate of RSK2 and an essential regulator of osteoblast biology; implication for Coffin-Lowry Syndrome. Cell 117, 387-398. doi: 10.1016/S0092-8674(04)00344-7

Yeh, C. R., Chiu, J. J., Lee, C. I., Lee, P. L., Shih, Y. T., Sun, J. S., et al. (2010). Estrogen augments shear stress-induced signaling and gene expression in osteoblast-like cells via estrogen receptor-mediated expression of beta1integrin. J. Bone Miner. Res. 25, 627-639. doi: 10.1359/jbmr.091008

Yen, M. L., Su, J. L., Chien, C. L., Tseng, K. W., Yang, C. Y., Chen, W. F., et al. (2005). Diosgenin induces hypoxia-inducible factor-1 activation and angiogenesis through estrogen receptor-related phosphatidylinositol 3kinase/Akt and p38 mitogen-activated protein kinase pathways in osteoblasts. Mol. Pharmacol. 68, 1061-1073. doi: 10.1124/mol.104.010082

Yu, B., Zhao, X., Yang, C., Crane, J., Xian, L., Lu, W., et al. (2012). Parathyroid hormone induces differentiation of mesenchymal stromal/stem cells by enhancing bone morphogenetic protein signaling. J. Bone Miner. Res. 27, 2001-2014. doi: 10.1002/jbmr.1663

Yuan, L., Sakamoto, N., Song, G., and Sato, M. (2012). Migration of human mesenchymal stem cells under low shear stress mediated by mitogenactivated protein kinase signaling. Stem Cells Dev. 21, 2520-2530. doi: $10.1089 /$ scd. 2012.0010

Yumoto, H., Hirao, K., Tominaga, T., Bando, N., Takahashi, K., and Matsuo, T. (2015). Electromagnetic wave irradiation promotes osteoblastic cell proliferation and up-regulates growth factors via activation of the ERK1/2 and p38 MAPK pathways. Cell. Physiol. Biochem. 35, 601-615. doi: $10.1159 / 000369722$

Zetser, A., Gredinger, E., and Bengal, E. (1999). p38 mitogen-activated protein kinase pathway promotes skeletal muscle differentiation. Participation of the Mef2c transcription factor. J. Biol. Chem. 274, 5193-5200. doi: $10.1074 /$ jbc. 274.8 .5193

Zhai, Z. J., Li, H. W., Liu, G. W., Qu, X. H., Tian, B., Yan, W., et al. (2014). Andrographolide suppresses RANKL-induced osteoclastogenesis in vitro and prevents inflammatory bone loss in vivo. Br. J. Pharmacol. 171, 663-675. doi: 10.1111/bph.12463

Zhang, P., Wu, Y., Dai, Q., Fang, B., and Jiang, L. (2013). p38-MAPK signaling pathway is not involved in osteogenic differentiation during early response of mesenchymal stem cells to continuous mechanical strain. Mol. Cell. Biochem. 378, 19-28. doi: 10.1007/s11010-013-1589-7

Zhang, X., Zhou, C., Zha, X., Xu, Z., Li, L., Liu, Y., et al. (2015). Apigenin promotes osteogenic differentiation of human mesenchymal stem cells through JNK and p38 MAPK pathways. Mol. Cell. Biochem. 407, 41-50. doi: 10.1007/s11010-0152452-9

Zhang, Y. Y., Mei, Z. Q., Wu, J. W., and Wang, Z. X. (2008). Enzymatic activity and substrate specificity of mitogen-activated protein kinase p38alpha in different phosphorylation states. J. Biol. Chem. 283, 26591-26601. doi: 10.1074/jbc.M801703200

Zhou, C., Liu, W., He, W., Wang, H., Chen, Q., and Song, H. (2015). Saikosaponin a inhibits RANKL-induced osteoclastogenesis by suppressing NF-kappaB and MAPK pathways. Int. Immunopharmacol. 25, 49-54. doi: 10.1016/j.intimp.2015.01.010

Zhou, F. H., Foster, B. K., Zhou, X. F., Cowin, A. J., and Xian, C. J. (2006). TNF-alpha mediates p38 MAP kinase activation and negatively regulates bone formation at the injured growth plate in rats. J. Bone Miner. Res. 21, 1075-1088. doi: 10.1359/jbmr.060410

Zhou, Y., Guan, X., Wang, H., Zhu, Z., Li, C., Wu, S., et al. (2013). Hypoxia induces osteogenic/angiogenic responses of bone marrow-derived mesenchymal stromal cells seeded on bone-derived scaffolds via ERK1/2 and p38 pathways. Biotechnol. Bioeng. 110, 1794-1804. doi: 10.1002/bit. 24827

Zhu, J., Siclari, V. A., Liu, F., Spatz, J. M., Chandra, A., Divieti Pajevic, P., et al. (2012). Amphiregulin-EGFR signaling mediates the migration of bone marrow mesenchymal progenitors toward PTH-stimulated osteoblasts and osteocytes. PLoS ONE 7:e50099. doi: 10.1371/journal.pone.0050099

Zou, W., Greenblatt, M. B., Shim, J. H., Kant, S., Zhai, B., Lotinun, S., et al. (2011). MLK3 regulates bone development downstream of the faciogenital dysplasia protein FGD1 in mice. J. Clin. Invest. 121, 4383-4392. doi: 10.1172/ JCI59041

Zuzarte-Luís, V., Montero, J. A., Rodriguez-Leon, J., Merino, R., Rodríguez-Rey, J. C., and Hurlé, J. M. (2004). A new role for BMP5 during limb development acting through the synergic activation of Smad and MAPK pathways. Dev. Biol. 272, 39-52. doi: 10.1016/j.ydbio.2004.04.015

Conflict of Interest Statement: The authors declare that the research was conducted in the absence of any commercial or financial relationships that could be construed as a potential conflict of interest.

Copyright (C) 2016 Rodríguez-Carballo, Gámez and Ventura. This is an open-access article distributed under the terms of the Creative Commons Attribution License (CC $B Y)$. The use, distribution or reproduction in other forums is permitted, provided the original author(s) or licensor are credited and that the original publication in this journal is cited, in accordance with accepted academic practice. No use, distribution or reproduction is permitted which does not comply with these terms. 